This item was submitted to Loughborough's Research Repository by the author.

Items in Figshare are protected by copyright, with all rights reserved, unless otherwise indicated.

\title{
Evaluating the importance of catchment hydrological parameters for urban surface water flood modelling using a simple hydro-inundation model
}

\section{PLEASE CITE THE PUBLISHED VERSION}

http://dx.doi.org/10.1016/j.jhydrol.2015.02.040

\section{PUBLISHER}

(C) Elsevier

VERSION

AM (Accepted Manuscript)

\section{PUBLISHER STATEMENT}

This work is made available according to the conditions of the Creative Commons Attribution-NonCommercialNoDerivatives 4.0 International (CC BY-NC-ND 4.0) licence. Full details of this licence are available at: https://creativecommons.org/licenses/by-nc-nd/4.0/

\section{LICENCE}

CC BY-NC-ND 4.0

\section{REPOSITORY RECORD}

Yu, Dapeng, and Tom J. Coulthard. 2019. "Evaluating the Importance of Catchment Hydrological Parameters for Urban Surface Water Flood Modelling Using a Simple Hydro-inundation Model”. figshare. https://hdl.handle.net/2134/17151. 
Evaluating the importance of catchment hydrological parameters for urban surface water flood modelling using a simple hydro-inundation model

3 Dapeng $\mathrm{Yu}^{1}$ and Tom J. Coulthard ${ }^{2}$

$4{ }^{1}$ Department of Geography, Loughborough University, Tel: 01509228191; Fax: 01509223930;

5 d.yu2@lboro.ac.uk

$6 \quad{ }^{2}$ Department of Geography, Environment and Earth Science, University of Hull

Abstract

9 The influence of catchment hydrological processes on urban flooding is often considered through river discharges at a source catchment outlet, negating the role of other upstream areas that may add to the

11 flooding.. Therefore, where multiple entry points exist at the urban upstream boundary, e.g. during extreme rainfall events when surface runoff dominates in the catchment, a hydro-inundation model becomes advantageous as it can integrate the hydrological processes with surface flow routing on the urban floodplain. This paper uses a hydro-inundation model (FloodMap-HydroInundation2D) to investigate the role of catchment hydrological parameters in urban surface water flooding. A scenario-based approach was undertaken and the June 2007 event occurred in Kingston Upon Hull, UK was used as a baseline simulation, for which a good range of data is available. After model sensitivity analysis and calibration, simulations were designed, considering the improvement of both the urban and rural land drainage and storage capacities. Results suggest the model is sensitive to the key hydrological parameter soil hydraulic conductivity. Sensitivity to mesh resolution and roughness parameterisation also agrees with previous studies on fluvial flood modelling. Furthermore, the improvement of drainage and storage capacity in the upstream rural area is able to alleviate the extent and magnitude of flooding in the downstream urban area. Similarly urban drainage and storage upgrade may also reduce the risks of flooding on site, albeit to a less extent compared to rural improvements. However, none of the improvement scenarios could remove the flow propagation completely. This study highlights that in some settings, urban surface water flood modelling is just as strongly controlled by rural factors (e.g. infiltration rate and water storage) as internal model parameters such

27 as roughness and mesh resolution. It serves as an important reminder to researchers simulating urban 28 flooding that it is not just the internal parameterisation that is important, but also the use of correct inputs from outside the area of study, especially for catchments with a mixture of urban and rural areas. 
31 Keywords: Hydro-inundation model; urban flooding; surface water flooding; pluvial flooding. 


\section{Introduction}

34 Flood risk managers and decision-makers often face the challenging tasks of designing effective mitigation and adaptation strategies in response to low-frequency and unexpected urban flooding arising from extreme storm events, during which, the combination of surface water runoff and storm sewer surcharge are the two major sources of inundation. Storm sewer flooding is due to the surcharge of excess water that can not be drained by the sewer system and is therefore usually localized. The modelling of storm sewer induced urban flooding has seen a great body of literature in the last few decades, with a range of modelling approaches developed including the 'dual-drainage modelling' (1D/2D) (Djordjević et al. 1991; Hsu et al. 2000; Schmitt et al. 2004) and the 1D/1D approach (Mark et al. 2004). Such approaches typically couple: (i) the solution of the 1D shallow water equations for the storm sewer systems; and (ii) a 1D or 2D representation of surface flow. These approaches are able to provide a good estimate of urban flood risks at the local scale. The accuracy of the model predictions depends on a number of factors, including the accuracy of: (i) the topographic data; (ii) inflow to the drainage inlets, usually derived from hydrological estimation; and (iii) the geometries of the storm sewer pipes. In comparison, direct surface water runoff in urban environments are less well studied. Surface water flooding may arise from rainfall-generated overland flow before the runoff enters watercourses or is captured by the sewer system. It is usually associated with high intensity rainfall (e.g. $>30 \mathrm{~mm} /$ hour), during which urban storm sewer drainage systems and surface watercourses may be overwhelmed, preventing drainage through artificial (e.g. pumping) or natural means (e.g. gravity). Moreover, even when fully functioning, urban storm sewer systems may not have the capacity to capture all the surface runoff through inlets during extreme events and direct surface runoff can overpass manholes and accumulate to form ponding in topographic depressions due to inlet efficiency (Aronica and Lanza 2005). In addition, surface water flooding can also originate from rural areas adjacent to the urban settlements where extreme rainfall runoff accumulates along flow paths without being captured by the land drainage/storage systems. Recently, 2D surface flow routing models have been used to simulate the urban surface water runoff originating from point sources (e.g. manholes), using synthetic or model-derived flow hydrographs (e.g. Mignot et al. 2006; Fewtrell et al. 2011). In these studies, the interaction between surface runoff and storm sewer is either considered as insignificant, or represented through a mass loss term determined based on the drainage capacity. Modelling 2D surface water runoff in urban catchment is challenging due to the 
needs to consider both the hydrological (e.g. precipitation, infiltration and evapotranspiration) and hydraulic processes (surface flow routing), in a topographically complex environment. The representation of spatiotemporal variation in precipitation, and effect of land characteristics (e.g. land use and soil type) is required for the former in order to calculate the right amount of rainfall runoff, while high-accuracy topographic data where topographic connectivity is preserved is essential for routing the surface runoff to the correct places.

More recently, researchers have incorporated direct precipitation into 2D flow routing models in urban environments. Such models can be termed as "hydro-inundation models" whereby hydrological processes are considered simultaneously with floodplain flow routing. Hydrological and inundation processes are two interlinked processes but they have so far been largely investigated in isolation, with hydrological outputs at the catchment-scale used as inputs to surface flow routing at the upstream boundary. Linking these two subsystems using a unified hydro-inundation model is a logical step towards integrated modelling, especially when multiple entry points exist at the catchment/floodplain boundary. The use of a hydro-inundation model is particularly advantageous for decision makers to evaluate the impact of catchment-wide hydrological processes on urban flood inundation. The role of land management scenarios (e.g. improved storage capacity and improved drainage) can be tested using such models. Whilst commercial software packages already offer such functions, represented by the surface water flood map produced by the EA (EA, 2013), research studies coupling hydrological and inundation processes are rare, especially in urban areas. Chen et al. (2009) used a nested approach to incorporate hourly rainfall on a $5 \mathrm{~km}$ grid upstream in the upstream catchment and a finer rainfall field of 15 -minute on a $2 \mathrm{~km}$ grid for hydraulic modelling in the downstream. A non-inertial model was used (URM, Chen et al. 2007) and the focus was placed on filtering rainfall events and considering future climate change scenarios derived from UKCP09 predictions. Sampson et al. (2013) presented a

84 modelling study of surface water flooding at a local scale $\left(0.5 \mathrm{~km}^{2}\right)$ with a uniform rainfall input and a synthetic single point culvert surcharge using a flood inundation model (LISFLOOD-FP), focusing on: (i) routing rainwater from elevated features; and (ii) comparison with commercial modelling packages.

87 Hydrological factors (e.g. infiltration and evapotranspiration) were not considered due to the solely urban nature of their study site, and validation was not undertaken due to limited data availability. In this study, we describe the application of a hydro-inundation model (FloodMap-HydroInundation2D) to investigate the 
importance of urban and rural land drainage/storage capacity on flood inundation in catchment with a mixture of urban and rural areas, using the June 2007 event in the city of Kingston upon Hull, UK as the baseline simulation.

\section{3}

\section{Methods}

\section{$95 \quad 2.1$ The hydro-inundation model used}

96 The model (FloodMap-HydroInundation2D) is developed based on the modified version (local inertial-based)

97 of FloodMap ( $\mathrm{Yu}$ and Lane 2006a), which is a two-dimensional flood inundation model designed for 98 modelling flood inundation over topographically complex floodplains. The model has been tested and 99 verified with a range of boundary conditions and in a number of environments (Yu 2005; Yu 2010; Tayefi et 100 al. 2007; Lane et al. 2008; Casas et al. 2010; Yin et al. 2013). It is modified to incorporate the key 101 hydrological processes during an urban storm event into surface flow routing, including infiltration and 102 evapotranspiration.

\section{$104 \quad$ 2.1.1 Surface flow routing}

105 The 2D flood inundation model (FloodMap-Inertial) takes the same structure as the inertial model of Bates et 106 al. (2010), but with a slightly different approach to the calculation of time step. Neglecting the convective 107 acceleration term in the Saint-Venant equation, the momentum equation becomes:

$108 \quad \frac{\partial q}{\partial t}+\frac{g h \partial(h+z)}{\partial x}+\frac{g n^{2} q^{2}}{R^{4 / 3} h}=0$

109 Where $q$ is the flow per unit width, $g$ is the acceleration due to gravity, $R$ is the hydraulic radius, $z$ is the bed 110 elevation, $h$ is the water depth and $n$ is the Manning's roughness coefficient. Discretizing the equation with 111 respect to time produces:

$112 \frac{q_{t+\Delta t}-q_{t}}{\Delta t}+\frac{g h_{t} \partial(h+z)}{\partial x}+\frac{g n^{2} q_{t}^{2}}{h_{t}^{7 / 3}}=0$

113 To further improve this, one of the $q_{t}$ in the friction term can be replaced by $q_{t+\Delta t}$ and this gives the explicit 114 expression of the flow at the next time step:

$q_{t+\Delta t}=\frac{q_{t}-g h_{t} \Delta t\left(\frac{\Delta\left(h_{t}+z\right)}{\Delta x}\right)}{\left(1+g h_{t} \Delta t n^{2} q_{t} / h_{t}^{10 / 3}\right)}$ 
The flow in the $\mathrm{x}$ and $\mathrm{y}$ directions is decoupled and take the same form. Flow is evaluated at the cell edges and depth at the centre.

FloodMap evaluates the flow directions in $\mathrm{x}$ and $\mathrm{y}$ for each pixel at each iteration based on the orthogonal slopes. The flow rate across a cell boundary is calculated using (3) for the two directions associated with the greatest orthogonal slope. Therefore, only positive flow is allowed in each direction. Net inflow is calculated for each pixel based on total inflow and outflow which can then be used to update water depth for the time step. Instead of using a global Courant-Freidrich-Levy Condition (where the time step for the next iteration is calculated based on the maximum water depth and velocity found at the last time step e.g. Bates and De Roo 2000; Yu and Lane 2006a), the Forward Courant-Freidrich-Levy Condition (FCFL) approach described in Yu and Lane (2011) for the diffusion-based version of FloodMap is used in the inertial model to calculate time step. The maximum time step that will satisfy the CFL condition for a given wet cell is calculated as:

$$
\Delta t_{i, j}<=\frac{w \times n \times\left(S_{i}^{2}+S_{j}^{2}\right)^{1 / 4}}{d^{0.67}\left(S_{i}+S_{j}\right)+\sqrt{g \times D \times n} \times\left(S_{i}^{2}+S_{j}^{2}\right)^{1 / 4}}
$$

where $w$ is the cell size, $d$ is the effective water depths, $S_{i}$ and $S_{j}$ are water surface slopes, and $i$ and $j$ are the indices for the flow direction in the $\mathrm{x}$ and $\mathrm{y}$ direction respectively. The effective water depth is defined as the difference between the higher water surface elevation and the higher bed elevation of two cells that exchange water. The minimum time step that satisfies the FCFL condition for all the wet cells is used as the global time step for this iteration. Comparison with the ATS scheme using the analytical solution of floodplain wetting over a horizontal plane used by Hunter et al. (2005), the FCFL condition was found to be less constraining due to the lower exponent ( 0.67 as opposed to 1.67$)$ on effective water depth in the denominator (Yu and Lane 2011). As the FCFL condition is not strictly the right stability criteria for an inertial system, this scheme still may not guarantee a stable solution, and thus may still produce unrealistic wave propagation. The universal time step calculated with FCFL may need to be scaled further by a coefficient, the value of which ranges between 0 exclusive and 1 inclusive. A scaling factor of $0.5-0.8$ was found to give stable solution to all the simulations carried out in this study and a scaling factor of 0.7 was used in all the simulations undertaken. 


\subsubsection{Infiltration and Evapotranspiration}

144 Infiltration over saturation is represented by the widely used Green-Ampt infiltration equation, which 145 approximates the rate of infiltration as a function of the capillary potential, porosity, hydraulic conductivity 146 and time, taking the following form:

$f(t)=K_{s}\left(\frac{\varphi_{f}+h_{o}}{a_{f}}+1\right)$

148 Where $K_{s}$ is the hydraulic conductivity of the soil at field saturation, $\varphi_{f}$ is the capillary potential across the 149 wetting front, $h_{0}$ is the ponding water on the soil surface, and $z_{f}$ is cumulative depth of infiltration. 150 Hydraulic conductivity is often used as a calibration parameter in hydrological studies.

Evapotranspiration is calculated using a simple seasonal sine curve for daily potential evapotranspiration (Calder et al. 1983) with the equation below:

$E_{p}=\overline{E_{p}}\left[1+\sin \left(\frac{36 i}{365}-90\right)\right]$

Where $\overline{E_{p}}$ is the mean daily potential evapotranspiration and $i$ is the day of the year.

For hydro-inundation modelling, the amount of evapotranspiration during storm and flooding conditions is in the order of 3-5 $\mathrm{mm} /$ day, a small amount compared to infiltration and drainage processes.

\subsubsection{Drainage capacity in urban areas}

Mass loss to the storm sewer system is considered in the model by its design capacity, usually corresponding to a rainfall event of certain intensity $(\mathrm{mm} / \mathrm{h})$ and return period. If the model is applied to an extreme event (defined here as a $>1$ in 100 year), it is reasonable to assume that the storm sewer system drains water away at the maximum design capacity. For each time step, the amount of runoff loss to the urban storm sewer systems is calculated by scaling the drainage capacity $(\mathrm{mm} / \mathrm{hour}$ ) for the time step. Distributed drainage capacity also can be incorporated into the model on a cell by cell basis. However, manholes and drains are not explicitly represented in the model (e.g. Liu et al. 2014). Rather, the drainage capacity is considered as a lump value that operates over a specific area, draining to its design capacity throughout that whole area. 


\subsection{Study site and the event}

The city of Kingston upon Hull (hereafter Hull) is located on the River Hull at its junction with the Humber estuary. The terrain of the city itself is low-lying, with ground elevation ranging between $2 \mathrm{~m}$ to $4 \mathrm{~m}$ AOD. The mean sea level in the East coast of the UK is above AOD and the Humber estuary experiences a tidal range of c.6m. Therefore, over $90 \%$ of the city is below the high tidal level. Until the mid 1960 's, a system of open drains and tidally operated gates drained the city, but these were replaced with a combined sewage and drainage system evacuated by three large pumping stations. As a result, the drainage system for the city of Hull is entirely pumped (Coulthard and Frostick, 2010). The city is protected from tidal inundation by embankments and flood walls along the estuary and by a tidal barrier operating on the River Hull to prevent the progression of high tides up the river that dissects the city. Following the modernisation of the drainage system in the 1960's and prior to 2007, significant fluvial and coastal flooding has been absent from recent history although it is anticipated that sea level rise and increased storminess might be increasing the risks of coastal flooding. In 2007, the city experienced widespread flooding from a pluvial event for $>>12$ hours, totalling $110 \mathrm{~mm}$. The $25^{\text {th }}$ June 2007 24-hour rainfall is estimated to be a one in 150 year (CEH Flood Estimation Handbook; Yorkshire Water pers. comm., Coulthard and Frostick 2010) and greater than 1 in 200 years by Hanna et al. (2008). Antecedent conditions were wet due to a 1 in 30 year event ten days previously. The $25^{\text {th }}$ June flooding caused damage to over 8600 residential and 1300 businesses, and flooded over 600 roads (Coulthard et al. 2007a). During the event, water was contained in the River Hull and it was reported that only the Setting Dyke, which is an open drain to the west of the city overtopped briefly (Coulthard et al. 2007a). Groundwater was greatly elevated but it was not found to cause flooding during this event. The major cause of the flooding is surface water runoff (Halcrow 2009) both locally in the urban area and through the rural lands surrounding the city. Hull has a storm sewer system with a design standard of 1 in 30 years $(70 \mathrm{~mm} /$ day, Coulthard et al. 2007a). However, due to the sheer magnitude of the 2007 event, although fully functioning during the event, the storm sewer system was overwhelmed and unable to drain the excess surface runoff. This event has prompted the suggestion that, for a low-lying coastal city such as Hull, a one in 30-year storm sewer system is insufficient, especially in the wake of the potential climate change and variability (Coulthard et al. 2007b). In this study, we focus on the worst hit areas to the west of the city (Figure 1) where surface runoff was found to be the most severe. 
Figure 1

2.3 Data availability and processing

\subsubsection{Topographic data}

204 Elevation data in Hull is available in the form of a high resolution (1 m) LiDAR dataset, processed by the 205 UK Environment Agency's National Centre for Environmental Data Surveillance in Twerton, Bath, to a vertical precision of $+/-25 \mathrm{~cm}$ throughout, and $+/-15 \mathrm{~cm}$ in low relief areas with solid reflectance surfaces.

\subsubsection{Precipitation data}

209 Within and in the vicinity of Hull, six rainfall gauging records are available from the UK Met Office and 210 Hull University, but only one is in the city itself. The rainfall hyetographs of the stations are shown in Figure 2112 , demonstrating the spatial and temporal heterogeneity of precipitation in the records. The 24-hour 212 precipitation total ranges between $51.6 \mathrm{~mm}$ (Cottingham) and $119.6 \mathrm{~mm}$ (Winestead). Considering the 213 degree of consistency within the data records, the gauging data at the Hull University (total $110 \mathrm{~mm}$ ) was 214 used in the modelling. It should be noted that this rainfall record is un-calibrated, and using data from a 215 single site is likely to introduce uncertainties into the representation of rainfall spatiotemporal characteristics. 216 However, given the size of the study site and the scenario-based nature of the modelling approach, this is 217 considered adequate.

Figure 2

\subsubsection{Observed inundation}

222 A set of observation data describing the inundation extent of the event is available, including: (i) the extent 223 of inundated areas provided by the UK Environment Agency and the Hull City Council, consisting of 224 information derived from various sources including ground survey and aerial photos; and (ii) buffer of houses flooded provided by the Hull City Council. The observation data within the study area are shown in Figure 3. Water depths are reported to be up to $3 \mathrm{~m}$ locally, but for most areas affected the depth is less than $1 \mathrm{~m}$ and many properties were flooded less than $50 \mathrm{~cm}$ (Coulthard and Frostick 2010). 
Figure 3

2.4 Simulation design

Digital Terrain Models (DTMs) of two resolutions $(10 \mathrm{~m}$ and $20 \mathrm{~m}$ ) were produced to test model sensitivity to topographic resolution. The total number of pixels in each DTM is 0.9 million and 0.2 million respectively, indicating the quadratic increase of the computational resources required with the fining of mesh resolution.

Roughness and hydraulic conductivity are the key parameters for model calibration. An initial screening was undertaken to constrain the possible range of values for these two parameters in simulating this particular flood event. A hydraulic conductivity $\left(K_{s}\right)$ value of between $0.001 \mathrm{~m} / \mathrm{h}$ and $0.005 \mathrm{~m} / \mathrm{h}$ was found to produce reasonable model response. Further justification to the choice of $K_{s}$ values is provided in Section 3.2 where model calibration is discussed. Model sensitivity to roughness parameterisation is evaluated by varying the 241 Manning's $n$ value $(0.01,0.02,0.03,0.04$ and 0.05$)$, while keeping the hydraulic conductivity at $0.005 \mathrm{~m} / \mathrm{h}$.

242 The default drainage capacity of the urban areas takes the design drainage capacity of the city, i.e. 70 $\mathrm{mm} /$ day, and that of the rural areas is set as $15 \mathrm{~mm} /$ day, based on the typical design capacity of $10 \mathrm{~mm} /$ day widely used in the lower rainfall areas of the UK (Trafford, 1971). This, in combination with the mesh resolution, generates 15 simulations, allowing the model response to mesh resolution and roughness parameterisation to be investigated.

Land drainage and storage capacity affects the amount of surface runoff that in turn may cause flooding. Improving the drainage and storage capacity through rural land management (e.g. tilting, piping and ponds) and urban drainage improvement (e.g. storm sewer retro-fit, SuDS, aqua-green and underground storm water storage) may result in reduced amounts of surface runoff. After testing the model sensitivity to mesh resolution and calibration with roughness and hydraulic conductivity parameters, simulations were designed, accounting for various urban and rural drainage and storage capacities and their combinations. Urban (80\%) and rural $(20 \%)$ areas were delineated based on the Ordnance Survey MasterMap dataset. Drainage and storage improvement scenarios were designed by considering: (i) an increase of urban drainage and storage 
capacity to $120 \mathrm{~mm} /$ day at a $10 \mathrm{~mm}$ interval (i.e. $80 \mathrm{~mm}, 90 \mathrm{~mm}, 100 \mathrm{~mm}, 110 \mathrm{~mm}$ and $120 \mathrm{~mm}$ ); and (ii) improvement of rural drainage/storage capacity up to $115 \mathrm{~mm} /$ day at a $20 \mathrm{~mm}$ interval (i.e. $35 \mathrm{~mm}, 55 \mathrm{~mm}$, $75 \mathrm{~mm}, 95 \mathrm{~mm}$ and $115 \mathrm{~mm}$ ). These are summarized in Table 1. It is noted that the values of drainage and storage improvement are rather optimistically designed if we consider typical drainage capacity alone (e.g. $30 \mathrm{~mm} / \mathrm{h}$ ). However, for both urban and rural environments, there is scope for innovative and 'extreme' storage improvement (e.g. Water Plazas and underground storm water storage) which will render the above design drainage and storage feasible.

It should be recognized that the impact of rural land drainage on river peak flow is highly uncertain and likely to be site specific, depending on the soil type, antecedent conditions and rainfall event (Blanc et al. 2012 and Robinson 1990). Interested readers could refer to the studies by Robinson (1990) and Blanc et al. (2012) for extensive review on the impact of land drainage. As we focus on surface water flooding, measures that improve land drainage and storage capacity are likely to exert a positive effect as it reduces surface runoff. However, it is uncertain whether such improvement will aggravate fluvial flooding.

\section{Table 1}

\section{Results}

\subsection{Sensitivity to roughness and mesh resolution}

Model sensitivty to the roughness parameter is evalauted by varying the Manning's $n$ value $(0.01,0.02,0.03$, 0.04 and 0.05 ). Figure 4 demonstrates the model response to the variation and in terms of inundation extent (Figure 4a), the model responds as expected for individual mesh resolution, with a higher roughness value slowing flood propagation. An $n$ value of 0.01 produces the largest inundation in all cases. However, inundation extent differs only marginally for $n$ values between 0.02 and 0.05 , suggesting that in this application the model is relatively insensitive to roughness specification. F statistic and RMSE (Figures $4 \mathrm{~b}$ and 4c) compare the temproal difference between the spatial distribution of inundated areas and water depths for simulations with an $n$ value of $0.02,0.03,0.04$ and 0.05 using the 0.01 simulation as the refence for each mesh resolution. The model becomes more sensitive when evaluated against $\mathrm{F}$ statistic and RMSE, demonstrating the spatial and temporal variability of the predicted wetted area and depth distribution. 
286 After a brief peak, the F statistic drops to a rather low level, suggesting a mismatch in the predicted 287 inundated areas during the initial wetting process. However, when the timing ( $8^{\text {th }}$ hour) of the F statistic peak 288 is cross-examined with the total inundation area (Figure 4a), it can be seen that this peak is associated with 289 minor wetted area. The F value gradually picks up with the onset of surface runoff. As the peak inundation 290 occurs (c. 16:00), the F statistic reaches the highest. Model's sensitivity to roughness when evaluated using F 291 stastistic suggests the varying flow velocity associated with different roughness values.

293 The magnitude of RMSE is relatively small $(<2.5 \mathrm{~cm})$ in all cases and varies over time and is a function of 294 the roughenss value. However, it should be noted that the RMSE is the aggragated depth variation from the 295 base simulation $(n=0.01)$ over the study area at a particular time. Therefore, the spatial distribution of depth 296 difference is not considered explicitly. Spatial variation of the depth prediction is expected and this will be 297 illustrated further.

Figure 4

Figure 5 explores the model sensitivity to mesh resolution also considering the roughness parameters. When the total inundation area is evaluated over time, the model is relatively insensitive to mesh size during the rising limb and demonstrates a certain degree of sensitivity during the falling. However, the sensitivity to mesh resolution is also a function of the roughness parameter, as roughness value increases the sensitivity decreases. Sensitivity is also reflected in the F statistic, however, the correlation between mesh resolution and roughness becomes notably weaker when the $\mathrm{F}$ statistic is used. There is a slight increase in the sensitivity with the increase of roughness value when F is considered. RMSE response is more complex, but consistent for $n$ values of $0.03,0.04$ and 0.05 . As F and RMSE are relative metrics, calculated against the reference simulation with an $n$ value of 0.01 for respective mesh resolution, comparing these for different resolutions might not reveal the sensitivity. 


\subsection{Model calibration and validation}

315 Given the marginal difference in the model sensitivity to mesh resolution when peak inundation is considered (Figure 4a) and accounting for computational efficiency, the $20 \mathrm{~m}$ DTM is used in the subsequent simulations. Manning's $n$ is kept at 0.03 , a value in the theoretical range of roughness specification. Whilst a uniform roughness value of 0.03 simplifies the representation, given the scenario-based nature of this study, it is regarded as an adequate assumption.

Due to the uncertainties in rainfall representation and drainage and storage capacity (both rural and urban), soil hydraulic conductivity $\left(K_{\varepsilon}\right)$ was used as a calibration parameter. This compensates for the simplified representation of rainfall and drainage/storage capacity and aims to produce the optimal match with the observation data for the base simulation.

Soil hydraulic conductivity can be determined either use empirically-based correlation methods or through in-situ hydraulic laboratory measurements. The latter is practically infeasible for urban catchments. We use empirically-based methods to estimate soil hydraulic conductivity in West Hull. Such methods typically associate $K_{s}$ with soil properties (texture, pore-size and grain size distribution) or soil mapping units (Oosterbaan and Nijland 1994). Surface deposit in Hull is characterised by alluvium and tidal flat deposits comprising of clay and silt, and major soil types include stony, silty or clay loams, characterised by fine silty material overlying lithoskeletal chalk usually occurring in well-drained areas (O'Donnell et al. 2004). The $K_{s}$ value for the study site is therefore determined based on the lower range of the typical $K_{s}$ suggested by

334 Smedema and Rycroft (1983) and through a calibration process, during which Fit statistic is used to evaluate the match in extent between the model prediction and observation (Figure 3). The final set of $K_{s}$ values tested include $0.001,0.002,0.003,0.004$ and $0.005(\mathrm{~m} / \mathrm{h})$, covering the lower range of the $K_{s}$ values suggested by Smedema and Rycroft (1983), reflecting the urbanized nature of the catchment. The results are shown in Figure 6.

The model was found to be very sensitive to the specification of hydraulic conductivity (Figure 6) and a small variation of this parameter results in a notable change in the amount of infiltration (Figure 6b) and 
extent of inundation (Figure 6a). The simulation with a Ks value of 0.001 is used as the reference simulation and RMSE and F are calculated over time. RMSE and F statistic (Figures $6 \mathrm{c}$ and $6 \mathrm{~d}$ ) also demonstrate the spatiotemporal variation of model predictions.

\section{5}

Figure 6

Furthermore, we decouple the main hydrological components into total rainfall, infiltration loss, evapotranspiration loss and drainage loss to evaluate the temporal changes in water balance in Figure 7 .

Figure 7

Model validation aims to reproduce the extent of inundation that best approximates the observed extent in the worst-hit areas, i.e. the urban areas adjacent to the rural lands to the west of the city. A hydraulic conductivity value of $0.003 \mathrm{~m} / \mathrm{h}$ was found to produce the best match, with an overall $\mathrm{F}$ value of $35 \%$. It should be noted that given the nature of surface water flooding, the observed data are likely to underestimate the extent of flooding, especially for isolated patches of flooded area. Indeed, the inundation extent collated by the EA and Council differs to a large extent (Figure 3). Therefore the relatively low F value may not be a good indication of the model performance. This will be further evaluated in section 4.2. The time series of inundation is shown in Figure 8. The temporal sequence of inundation is reproduced well in the simulation. Excess water that cannot be drained away due to the limited urban and rural drainage capacity is routed to the topographic lows and accumulates to the edge of the urban areas following topographic gradients (10:00 Figure 8). Water then enters the worst-hit regions and propagates further into the city centre (12:00 Figure 8). Water starts to recede at around 16:00 but there remain areas of inundation untill late in the day (22:00 Figure 8).

Figure 8 
One immediate question following this significant flood event is whether improved urban drainage capacity

371 through pumping could alleviate its impact. The Final Independent Report (Coulthard et al. 2007) on the flood recommended that designs based on industry standards to protect from a 1 in 30 years storm event may not be adequate and additional capacity should be considered due to potential climate change and variability.

374 The Interim Independent Report (Coulthard et al. 2007) commissioned by the City Council suggested that to 375 slow down the addition of water to the drainage systems, temporary reservoirs could be created. Strategic interception of surface water could also be considered for routing the excess water to storage areas. In the

We undertook simulations to evaluate the potential impact of improved drainage and storage capacity in the urban areas. Urban drainage and storage improvement scenarios consider capacity increase from the current $70 \mathrm{~mm} /$ day to $120 \mathrm{~mm} /$ day at a $10 \mathrm{~mm}$ interval. The total inundated area is shown in Figure 9a for the baseline simulation and the scenarios. This is shown in comparison with the combination of: (i) a medium improvement of urban and rural drainage/storage to $100 \mathrm{~mm}$ /day and $75 \mathrm{~mm} /$ day respectively (dotted red line); and (ii) the optimal improvement of urban and rural drainage/storage to $120 \mathrm{~mm} /$ day and $115 \mathrm{~mm} /$ day respectively (solid red line). The predicted extent for each scenario over time is compared to the baseline simulation using the Fit statistic and this is shown in Figure 9b. Figure 9c shows the global derivation over time for the depth prediction in each scenario compared to the baseline simulation. As expected, the total inundated area decreases with the improvement of drainage capacity. An increase to $120 \mathrm{~mm} /$ day results in a marked reduction $(40 \%)$ of the peak inundation extent from the default simulation. This is also reflected in the F statistic.

Figure 9

394 In terms of the predicted water depth, although the magnitude of RMSE (overall deviation from the default simulation) is relatively small (Figure 9c), the spatial distribution of the depth difference suggests big variations in the reduction magnitude across the study area (Figures 9). The difference is localized in places where water depth is high in the default simulation. 
401 Water depth over time is plotted (Figure 11) for: (i) discrete points along the two main flow pathways 402 leading to the urban areas (P1-P5 and P6-P10); (ii) one point at the edge of the urban area (P11); and (iii) one 403 point in the city centre (P12). Among the points, P2 and P11 are located in rural areas. Points 1-5, and points 404 6-10 follow the two main flow pathways leading to the worst-hit areas respectively. Depth profiles 405 demonstrate the rapid response to precipitation in the headwaters (P1, P2, P6 and P7), during both the rising 406 and falling limbs of the flood event. Water depth rises fast in the worst-hit areas but the receding phrase is 407 prolonged as water accumulates to the local topographic lows (P3, P4, and P10). As expected, the urban 408 drainage capacity does not directly affect the point depths in the rural areas (P11), except for places that 409 urban water feeds to (P2). Sensitivity to urban drainage/storage capacity is more pronounced for points in the 410 city centre where water accumulates (P3, P4, P5, P10 and P12).

Figure 11

\subsection{Effects of improved rural land drainage and storage}

415 Surface water runoff from rural land adjacent to the urban settlement is the major source of flooding for 416 West Hull during the event. Upgrading the urban drainage and storage capacities may reduce flooding in the 417 city centre itself. However, it will not affect the amount of water entering the city from the adjacent rural 418 land to the west. Intercepting surface runoff from rural land is seen as a potentially useful measure for managing surface flood risks in Hull (Coulthard et al. 2007; Hull Council 2009). Modelling work undertaken in the Council's Surface Water Management Plan suggests that preventing overland flow entering the urban area by means of embankments or walls could have significant benefits. Two options were explored including an embankment to the west of A164 and using a golf course adjacent to the city centre as storage area in conjunction with an embankment (Figure 3). Apart from creating temporary water storages on the

424 floodplain, improving land drainage and storage capacity could also be considered in conjunction with other options. Instead of assessing the effectiveness of individual/combined options, we focus on their net impact on the total amount of water entering the urban areas. In this way, the combined impact of measures taken in the rural areas is simplified into a reduced amount of floodwater entering the urban area from various entry 
points (Figure 8). In a similar way to the investigation of urban drainage and storage capacity, the potential impact of improved rural land drainage and storage capacity was evaluated, based on five improvement scenarios from $15 \mathrm{~mm} /$ day to $115 \mathrm{~mm} /$ day at a $20 \mathrm{~mm}$ interval. The comparison with the default simulation is shown in Figure 12, alongside with the combination of: (i) a medium improvement of urban and rural drainage and storage to $100 \mathrm{~mm} /$ day and $75 \mathrm{~mm}$ /day respectively; and (ii) the optimal improvement of urban and rural drainage and storage to $120 \mathrm{~mm} /$ day and $115 \mathrm{~mm} /$ day respectively.

Figure 12

The reduction of maximum water depth with an improved rural land drainage and storage capacity from 15 $\mathrm{mm} /$ day to $55 \mathrm{~mm} /$ day and $115 \mathrm{~mm} /$ day is shown in Figures $11 \mathrm{a}$ and $11 \mathrm{~b}$ respectively. A moderate improvement to $55 \mathrm{~mm} /$ day results in notable reduction of water depth, especially in the Derringham area (Figure 3). The difference becomes much more pronounced when the drainage and storage capacity of the 441 rural land is increased to $115 \mathrm{~mm} /$ day.

Figure 13

445 The point depth profiles over time are shown in Figure 14 for different drainage and storage improvement 446 scenarios. The patterns are as expected but none of the scenarios result in substantially reduced water depth 447 for the points investigated, except point 5.

Figure 14

\section{Discussion}

\subsection{Sensitivity analysis and model calibration}

453 Model sensitivity to mesh resolution and roughness parameter reveals an interesting model response in 454 comparison to studies in fluvial flood modelling. Yu and Lane (2006a) reported greater inundation with a coarser mesh, for a relatively urban site with extended but laterally confined floodplain. In an application to a small urban district considering surface flooding due to sewer surcharge, Ozdemir et al. (2013) found that a 
finer mesh allows water to propagate along "channels" that form at the road edge, thus resulting in greater inundation. The former finding can be explained by the simplified nature of a diffusion-based inundation model, while the latter is associated with the degree of details in the representation of urban features that control flow propagation. With the additional consideration of hydrological processes such as precipitation, infiltration and evapotranspiration, the surface flow routing demonstrates various degrees of sensitivity to mesh resolution and roughness parameter when evaluated against different metrics. The sensitivity is therefore two-fold. On one hand, the model is rather insensitive to varying mesh sizes and roughness values (Figure 4 and Figure 5), when the inundation area is considered. On the other, the spatial metrics (i.e. F and RMSE) demonstrate much greater degree of spatial/temporal variability in the predication than the global metric (i.e. total inundated area), suggesting model's sensitivity to mesh resolution and roughness specification. Figure 15 shows the prediction of maximum water depth reached for the whole study area and in a subset, for the $5 \mathrm{~m}, 10 \mathrm{~m}, 50 \mathrm{~m}$ and $100 \mathrm{~m}$ mesh respectively. The "channel" effect exerted by a finer mesh reported in Ozdemir et al. (2013) can be confirmed from this. As the inertial model used in this study differs from $\mathrm{Yu}$ and Lane (2006a) due to the additional consideration of momentum terms in the governing 471 equation, the response to mesh resolution might change and future studies could be undertaken to explore any difference.

474 Figure 15 also illustrates the deterioration in the details of prediction if a $50 \mathrm{~m}$ or $100 \mathrm{~m}$ DEM is used in the 475 simulation. Systematic evaluations of the sensitivity to roughness and mesh resolution for fluvial flood 476 inundation models have been undertaken in previous studies (e.g. Yu and Lane 2006a; Ozdemir et al. 2013). 477 However, as hydro-inundation modelling is relatively new, studies in this area are rather limited. This study 478 focuses on finer meshes for an urban site. Future studies could be directed to evaluate DEM of various mesh 479 resolution and in a range of environments, to better understand the interaction between roughness 480 parameterisation and topographical representation. 
Model calibration shows that the model is highly sensitive to soil hydraulic conductivity $\left(K_{s}\right)$. With a 0.001

$\mathrm{m} / \mathrm{h}$ decrease of $K_{s}$, an average increase of 1.65 sq. $\mathrm{km}$ of peak inundated area is predicted (Figure 6a). This is due to the amount of reduced infiltration associated with a smaller hydraulic conductivity value (Figure 6b). Global metric RMSE shows notable difference between simulations (Figure 6c) and spatial comparison (F) of extent shows a similar trend (Figure 6d). The water balance profiles shown in Figure 7 corroborate those in Figure 6, suggesting that the model is highly sensitive to hydraulic conductivity, a key parameter in model calibration.

\subsection{Model evaluation and uncertainty analysis}

493 Although reconstruction of the flooding temporal sequence proved to be difficult due the fast-developing nature of surface water flooding and the challenges in accounting for the temporal and spatial dynamics, discrete information on the timing of flooding is available from various sources. The Hull City Council reported that, from 6:00 am, calls for emergency assistance quickly reached a peak of around 100 an hour and this level were sustained till 9:00 pm, with a Major Incident being declared at 09:30 am. In terms of the operation of the drainage system, it was reported that the inlet penstocks to West Hull Pumping Station were opened at approximately 7:00 am. Between 8:00 am and 8:15 am, the levels in the sumps for West Hull pumping station rose by $6 \mathrm{~m}$ from approximately $-1 \mathrm{~m}$ (Coulthard et al. 2007), indicating when water discharged into the pumping station wells and the pumps started. It is likely that the sewers in West Hull were fully surcharged when the pumps in West Hull started (Coulthard et al. 2007). The temporal information available agrees in general with the model predictions (Figure 8). However due to the resolution of the information, a statistical evaluation is not possible.

Comparisons between model predictions and observation data prove challenging due to the uncertainties in both. Observation data are likely to be incomplete and uncertain due to the challenges associated with gaining a full picture of pluvial flooding - which is often localized and fast-developing. This becomes apparent when the inundation extents collated by the EA and Council are compared (Figure 3). Large discrepancy can be noted in places. Furthermore, the accuracy of model prediction can be equally uncertain, 511 due largely to: (i) the quality of the input data, including the representation of spatial and temporal 
characteristic of precipitation, and topography; and (ii) simplified treatment of infiltration and negligence of

513 flooding from pluvial sources (i.e. drains). Despite the relative small size of the catchment (12 km by $7 \mathrm{~km}$ ),

514 variability in the spatial and temporal distribution of rainfall is expected. A single rainfall time series

515 immediately adjacent to the study site to the northeast is used in the simulation and it is likely that this has

516 likely introduced some errors to the representation of rainfall, especially in the rural regions to the west. The

517 use of high resolution radar-derived precipitation data might provide a more accurate representation though

518 this is not without its own uncertainties. Uncertainty is also present in the topographical data with a vertical 519 error of $+/-15-20 \mathrm{~cm}$ in the original LiDAR dataset. Sensitivity to mesh resolution suggests that, although the 520 difference in the total inundated area is similar, the spatial and temporal distribution of the predicted wet area 521 and water depth can vary to a large extent (Figure 4). A similar conclusion can be drawn with regards to the 522 roughness specification (Figure 4) where the model is relatively sensitive to roughness when evaluated 523 against the Fit statistic but less so when evaluated against the total inundation area. Despite this sensitivity, 524 the use of $20 \mathrm{~m}$ DTM still captures the spatial dynamics of surface flow routing.

There are also uncertainties in the process representation. The model assumes runoff due to infiltration excess dominates. Furthermore, surcharge from storm sewers is not considered by the model, but rather, a drainage capacity coefficient is used to represent the effect of drainage. Errors are expected with this approach, particularly at the local scale. The uncertainties involved in the process representation are offset during model calibration, when soil hydraulic conductivity is adjusted aiming to reproduce the observed 531 flooded areas, with a focus on the Derringham Area. It is recognized that soil hydraulic conductivity is a complex coefficient to determine, especially for an urban catchment like West Hull. However, a uniform hydraulic conductivity is used in the simulations and we did not attempt to represent the spatial variation of soil hydraulic conductivity due to the complexity involved in determining $K_{s}$ for urban catchment and the simplified nature of the model.

\subsection{Effects of urban and rural drainage and storage capacity}

Improvement to urban drainage and storage capacity is regarded as a potential measure to reduce the risks of catastrophic pluvial flood events in Hull (Hull Council 2009). Results suggest that improving drainage and storage capacity indeed could reduce the extent of inundation (Figure 9), but due to the magnitude of the 
event and the contribution of flood water from rural land, it may not completely drain the excess surface water, even with an increase of capacity to $120 \mathrm{~mm} /$ day. Though for localized ponding with no inflow from rural land (e.g. Points 5 and 12) this increase in capacity would be effective. It should be noted that we assume that the drainage system functions throughout a flood event to its full capacity. However, it is possible that in many situations, the actual drainage capacity could be degraded by malfunctioning pumps or blocked drains.

\subsection{Effect of improved rural land drainage and storage capacity}

When the rural land drainage and storage improvement scenarios are investigated, greater sensitivity is noted compared to the urban improvement scenarios, both globally (Figure 13) and at discrete points along the two main flow pathways (Figure 14). Comparing the scenarios of improved rural drainage/storage capacity (Figure 13) with urban drainage/storage scenarios of similar magnitude, it is clear that areas adjacent to the rural parts benefit most from rural intervention. These areas (e.g. Derringham Park, Figure 1) were amongst the worst-hit during the 2007 flood. Mass balance analysis in Figure 9d and Figure 12d suggests that a 10 $\mathrm{mm}$ improvement in urban areas has a similar effect on water balance as a $20 \mathrm{~mm}$ improvement in rural areas. Given the size ratio between the urban and rural areas in this case study (4:1), the rural improvement can be regarded as more effective on a unit area basis. In other words, a $20 \mathrm{~mm}$ improvement over one-unit rural area is as effective as a $10 \mathrm{~mm}$ improvement over four-unit urban area in reducing surface water for this specific site.

Furthermore, comparing Figure $10 \mathrm{~b}$ with Figure 13b, although similar in the capacity to reduce total volume of surface water as shown in Figures $9 \mathrm{~d}$ and $12 \mathrm{~d}$, a $40 \mathrm{~mm}$ rural improvement (Figure 13b) is significantly more effective in reducing maximum flood (both depth and extent) than a $20 \mathrm{~mm}$ urban improvement (Figure 10b).

Combining urban land drainage and storage improvement, the water depth can be reduced substantially. However, none of the scenarios could reduce surface runoff completely. This is not surprising when the magnitude of the flood event and the size ratio of rural to urban area (1:4) are considered. It is expected that 
improved rural land drainage and storage capacity will become more effective for larger catchments and lower-intensity rainfall events.

\subsection{Process representation}

573 The model treats the drainage capacity using a simplified approach and assumes a uniform mass loss for

574 individual pixels to represent the sewer capacity. A similar method is used by Mignot et al. (2006), where 575 drainage capacity is subtracted from the model-derived flow hydrographs in two inlets of an urban site to represent the effect of storm sewer drainage in the upstream of the city. Although the total volume of water lost to storm sewers is expected to be reasonably well represented, the temporal changes in capacity of the storm sewer network at the local scale will be simplified due to the interaction at the surface/sewer boundaries (manholes). Therefore, this may over- or under-estimate the amount of mass loss to the storm sewer systems. Due to the intensity and magnitude of the storm simulated and observations during the flood, the drainage capacity was reached early on in the event. Therefore the simulations may have overestimated the mass loss to storm sewers. Further modifications to the model may use ideas from the rational or LloydDavies equation (Hamill 2010) widely used in the design of storm sewer systems, which takes the form of $Q_{p}=C i A$, where $Q_{p}$ is peak discharge to a sewer inlet; $A$ is the catchment area; $C$ is a coefficient of runoff representing the characteristics of the catchment (e.g. impermeability); and $i$ is the rainfall intensity, which is calculated as the average rainfall during the time of concentration, defined as the total time required for rain falling at the catchment boundary to flow to the first sewer and then carried through the sewer system to the design point. The rational method is essentially a lump-model that translates rainfall into runoff based on sub-catchment characteristics while relating rainfall intensity to time of concentration. The effect of coefficient of runoff $(C)$ is represented in this study in a distributed way using the combination of infiltration capacity and evapotranspiration, with the former being related to land uses. Routing runoff explicitly improves the representation of runoff timing. However, the use of drainage capacity on a cell-by-cell basis assumes storm sewer explicitly drains rainfall at every single pixel, whilst in reality, only at certain points (manhole inlets), rainfall-runoff is drained by the sewer system. As a result, overestimation of drainage loss is expected with the current approach as the timing of flow through the system is not considered explicitly. The extent of overestimation depends on the interplay between rainfall intensity, topographic gradient and parameters used in the modelling. However, the loss overestimation should diminish if the simulation is 
allowed to run long enough as the sewers capture the runoff (e.g. in this case study). An alternative approach

to the cell-by-cell representation is to consider the actual locations of manhole inlets and use empirical equations to calculate the amount of water drained at the inlets.

Finally, we note that the choice of drainage capacity adopted for a particular simulation should correspond to the duration of an event. For shorter duration events, the design standard corresponding to the event duration should be used instead of scaling the daily design standard as it is a parameter that cannot be scaled linearly with time. In this study, we used the daily drainage design standard $(70 \mathrm{~mm} /$ day in Hull) to estimate drainage loss. As the rainfall lasted for most of the day (Figure 2), the daily design capacity is thought to be a valid representation. Further studies could be directed to evaluate alternative approaches to representing storm sewer design capacity, e.g. adopting temporally-varying hourly design capacity according to the rainfall pattern observed in the rainfall hyetograph.

\section{Conclusion}

This paper presents the application of a simple urban hydro-inundation model, coupling hydrological processes within an inertial-based surface flow routing model. After sensitivity testing and model calibration using the June 2007 flood event occurred in the City of Kingston upon Hull, UK, the application focuses on evaluating the effect of improved drainage and storage capacities at both the urban and rural areas.

617 Sensitivity analysis reveals the danger of using a global metric (e.g. inundation extent) to evaluate model sensitivity, as when using inundation extent, we found that the peak inundation varies only marginally. However, a comparison of distributed flood areas show the model is sensitive to both mesh resolution and roughness specification. The results obtained from the combined hydrological/hydraulic modelling complement previous studies on scaling issues in flood inundation modelling (e.g. Yu and Lane 2006a; Ozdemir et al. 2013). It is expected that the degree of sensitivity to mesh resolution and roughness is also associated with the topographic characteristic of the study site. With a sloped terrain, the sensitivity will likely be magnified as compared to a mild sloped terrain. The model was calibrated using soil hydraulic conductivity against the reported inundated areas collated from two sources (EA and Hull Council) and the timeline of the event. Results highlight the challenges in validating surface water flood modelling in urban 
areas. This is primarily due to the nature of surface water induced urban flooding. Such events are often unexpected and sudden in nature, characterised by shallow water depth and local ponding. As this study shows, it is therefore very important to include not only the urban areas but the rural/suburban areas that may contribute to the drainage area and flooding. This study clearly illustrates how the correct parameterisation of infiltration and water loss in the contributing hills west of Hull are vital for successful model performance.

Overall, model performance is just as strongly controlled by these rural factors as internal model parameters such as roughness. This serves as an important reminder to researchers simulating urban flooding that it is not just the internal parameterisation that is important, but also to use the correct inputs of water from outside the area of study, the rationale that behind tightly coupling catchment hydrological processes and urban flood inundation.

Future work should be directed towards obtaining high resolution and good quality observation data for model validation. Calibration also highlights the needs for further improvement of the modelling approach, including improved representation of drainage capacity and precipitation, and improved computational efficiency to allow for finer topographic data to be used in the simulation.

643 The scenario-based approach used to evaluate the effect of drainage and storage capacity provides some 644 useful insight into the potential adaptation measures to surface water flooding and their effectiveness. Such 645 measures are often site-specific. This paper used a simplified parameter (i.e. drainage and storage capacity) 646 to represent the bulk effect of improved urban and rural drainage and storage capacities. Improved drainage 647 and storage capacities result in corresponding reductions of flood extent and magnitude as expected. 648 However, none of the scenarios result in complete drainage. Due to the magnitude of the flood event 649 considered and the relative size of the rural areas, the findings are therefore limited to the particular 650 catchment and event. Future studies could be undertaken to evaluate: (i) the impacts of drainage and storage 651 capacity in catchments with varying urban/rural size ratio; (ii) the response of a catchment to precipitation of 652 varying magnitude, and spatiotemporal characteristics; and (iii) the alternative measures to alleviate the potential impacts of surface flood risks. 
656 The author wishes to thank two anonymous reviewers who provided very useful and constructive comments 657 on the paper. The author also thanks the editors who processed the submission. 
660

661

662

663

664

665

666

667

668

669

670

671

672

673

674

675

676

677

678

679

680

681

682

683

684

685

686

687

688

689

690

691

692

693

694

695

Reference

Aronica, G.T. and Lanza, L.G. 2005. Drainage efficiency in urban areas: a case study. Hydrological Processes, 19(5):1105-1119.

Bates, P.D., Horritt, M., and Fewtrell, T. 2010. A simple inertial formulation of the shallow water equations for efficient two-dimensional flood inundation modelling. Journal of Hydrology, 387(1-2): 33-45.

Blanc, J., Arthur, S., Wright, G. and Beevers, L. 2012. Natural flood management (NFM) knowledge system: Part 3 - The effect of land drainage on flood risk and farming practice. Scotland's Centre of Expertise for Waters, final report, 38pp.

Calder, I.R., Harding, R.J. and Rosier, P.T.W. 1983. An objective assessment of soil moisture deficit models. Journal of Hydrology, 60: 329-355.

Casas, A., Lane, S.N., Yu, D. and Benito, G. 2010. A method for parameterising roughness and topographic sub-grid effects in hydraulic modelling from LiDAR data. Hydrology and Earth System Sciences, 14(8): 1567-1579.

Chen, A.S., Djordjević, S., Leandro, J. and Savić, D., 2007. The urban inundation model with bidirectional flow interaction between 2D overland surface and 1D sewer networks, NOVATECH 2007, Lyon, France, pp. 465-472.

Chen, A.S., Djordjević, S., Fowler, H.J., Burton, A., Walsh, C., Harvey, H., Hall, J., Dawson, R. and Wood, G. 2009. Pluvial flood modelling of the South East London Resilience Zone in the community Resilience to Extreme Weather (CREW) Project. 44th Flood and Coastal Risk Management Conference 2009, Telford, UK.

Coulthard, T.J. and Frostick, L.E. 2010. The Hull floods of 2007: implications for the governance and management of urban drainage systems. Journal of Flood Risk Management, 1-9.

Coulthard T.J., Frostick, L.E., Hardcastle, H., Jones, K., Rogers, D. and Scott, M. 2007a. The 2007 floods in Hull: Interim Report by the Independent Review Body. Hull City Council, 36pp.

Coulthard T.J., Frostick, L.E., Hardcastle, H., Jones, K., Rogers, D., Scott, M. and Bankoff, G. 2007b. The 2007 floods in Hull: Final Report by the Independent Review Body. Hull City Council, 68pp.

Djordjević, S., Ivetić, M., Maksimović, C., and Rajcević, A. 1991. An approach to the simulation of street flooding in the modeling of surcharged flow in storm sewers. Proceedings: New Technologies in Urban Drainage UDT, Maksimovic, Editor, Elsevier Publishers, 101-108.

Environment Agency UK, 2013. What is the updated Flood Map for Surface Water?

Fewtrell, T.J., Duncan, A., Sampson, C., Neal, J.C. and Bates, P.D. 2011. Benchmarking urban flood models of varying complexity and scale using high resolution terrestrial LiDAR data. Physics and Chemistry of the Earth, 36: 281-291.

Hamill, L. 2010. Understanding hydraulics, $3^{\text {rd }}$ edition. Palgrave and Macmillan. pp631.

Hanna, E., Mayes, J., Beswick, M., Prior, J. and Wood, L. 2008. An analysis of the extreme rainfall in Yorkshire, June 2007, and its rarity. Weather, 63(9):253-260. 
Hsu, M.H., Chen, S.H., and Chang, T.J. 2000. Inundation simulation for urban drainage basin with storm sewer system. Journal of Hydrology, 234, 21-37.

Hull Council. 2009. Surface Water Management Plan and Aqua Green Project. 72pp.

Lane, S.N., Reid, S.C., Tayefi, V., Yu, D., Hardy, R.J. 2008. Reconceptualising coarse sediment delivery problems in rivers as catchment-scale and diffuse. Geomorphology, 98(34): 227-249.

Liu, L, Liu, Y, Wang, X, Yu, D, Liu, K, Huang, H, Hu, G (2014) Developing an effective 2-D urban flood

\section{Sci. Discuss, 2, pp.6173-6199.}

Mark, O., Weesakul, S., Apirumanekul, C., Aroonnet, S.B., and Djordjević, S. 2004. Potential and limitations of 1D modelling of urban flooding. Journal of Hydrology, 299(3-4): 284-299.

Mignot, E., Paquier, A. and Haider, S. 2006. Modelling floods in a dense urban area using 2D shallow water equations. Journal of Hydrology, 327:186-199.

Oosterbaan, R.J. and Nijland H.J. 1994. Determining the saturated hydraulic conductivity. Chapter 12: In Ritzema, H.P. (Ed.), Drainage Principles and Applications. International Institute for Land Reclamation and Improvement (ILRI), Publication 16, second revised edition, Wageningen, The Netherlands.

O'Donnell, K.E., Freestone, S.E., Brown, S.E. 2004. Geochemical baseline data for the urban area of Kingston-upon-Hull. Urban Geoscience and Geological Hazards Programme, Internal Report IR/02/08. British Geological Survey, 61pp.

Ozdemir, H., Sampson, C., de Almeida, Gustavo A.M. and Bates, P.D. 2013. Evaluating scale and roughness effects in urban flood modelling using terrestrial LIDAR data. Hydrology and Earth System Sciences, 10: 5903-5942.

Robinson, M. 1990. Impact of land drainage on river flows. Institute of Hydrology, Wallingford, UK. 233pp.s

Schmitt, T.G., Thomas, M. and Ettrich, N. 2004. Analysis and modelling of flooding in urban drainage systems. Journal of Hydrology, 299(3-4): 300-311.

Sampson, C., Bates, P.B., Neal, J.C. and Horritt, M.S. 2013. An automated routing methodology to enable direct rainfall in high resolution shallow water models. Hydrological Processes, 27: 467-476.

Seyoum, S.D., Vojinovic Z., Price R.K. and Weesakul S. 2012. Coupled 1D and Noninertia 2D Flood Inundation Model for Simulation of Urban Flooding. Journal of Hydraulic Engineering, 138: 23-24.

Tayefi, V., Lane, S.N., Hardy, R.J. and Yu, D. 2007. A comparison of one- and two-dimensional approaches to modelling flood inundation over complex upland floodplains. Hydrological Processes, 21(23): 31903202 .

Trafford. B.D. 1971 Agricultural land drainage. Welsh Soils Discussion Group Report 12: 68-84.

Yin, J., Yu, D., Yin, Z.E., Wang, J. and Xu, S.Y. 2013. Modelling the combined impacts of sea-level rise and land subsidence on storm tides induced flooding of the Huangpu River in Shanghai, China. Climatic Change, 119(3-4): 919-932.

Yu, D. 2005. Two-dimensional diffusion wave modelling of structurally complex floodplains, Ph.D Thesis, School of Geography, University of Leeds, U.K. 
734 Yu, D. and Lane S.N. 2006a. Urban fluvial flood modelling using a two-dimensional diffusion wave treatment, part 1: mesh resolution effects. Hydrological Processes, 20(7): 1541-1565.

736 Yu, D. and Lane S.N. 2006b. Urban fluvial flood modelling using a two-dimensional diffusion wave treatment, part 2: development of a sub grid-scale treatment. Hydrological Processes, 20(7): 1567-1583.

738 Yu, D. 2010. Parallelization of a two-dimensional flood inundation model based on domain

739 decomposition. Environmental Modelling and Software, 25(8): 935-945.

740 Yu, D. and Lane S.N. 2011. Interaction between subgrid-scale resolution, feature representation and grid741 scale resolution in flood inundation modelling. Hydrological Processes, 25(1): 36-53. 
745 List of tables

746 Table 1: Baseline simulation and scenarios with various urban and rural drainage and storage capacities.

\begin{tabular}{lcc}
\hline Scenarios & $\begin{array}{c}\text { Urban drainage and } \\
\text { storage capacity (UD) } \\
\text { (mm per day) }\end{array}$ & $\begin{array}{c}\text { Rural drainage and } \\
\text { storage capacity (RD) } \\
\text { (mm per day) }\end{array}$ \\
\hline A: Base simulation, assuming urban storm sewer system functions at its & 70 & 15 \\
full capacity (70 mm/day) and the rural land drainage and storage has a & & \\
capacity of 15 mm/day during the event. & & 15 \\
\hline B: Improved drainage and storage capacity in urban areas (e.g. engineering & 80 & 15 \\
measures; swales and balancing ponds). & 90 & 15 \\
& 100 & 15 \\
& 110 & 15 \\
\hline C: Improved rural land drainage and storage capacity (e.g. land & 120 & 35 \\
management; flow interceptors and storage areas). & 70 & 55 \\
& 70 & 75 \\
& 70 & 95 \\
\hline D: Combined BandC & 70 & 115 \\
\hline
\end{tabular}

\section{7}

748

749 
$751 \quad$ List of figures

752

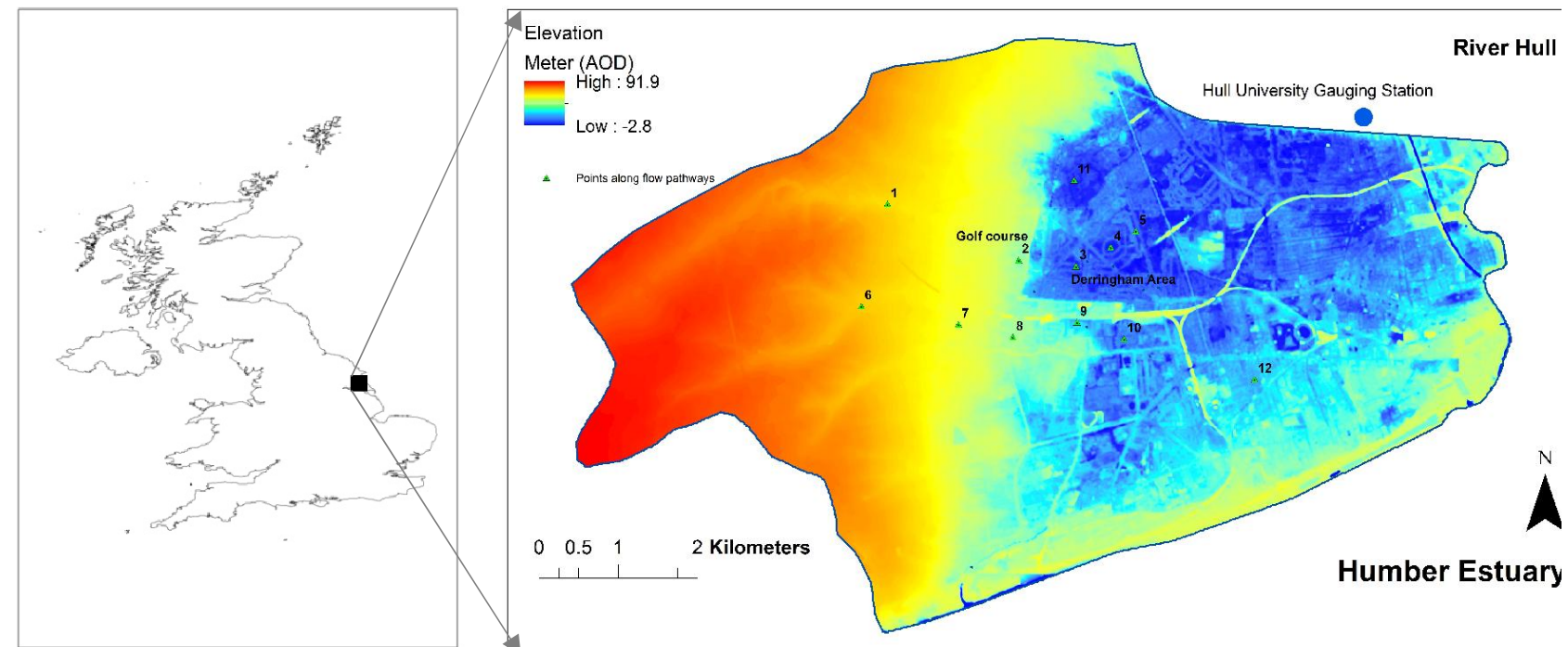

753 Figure 1: Digital Elevation Model of the West part of the City of Kingston upon Hull, UK and contributing catchment 754 areas. Points are locations where the depths are analysed.

755 

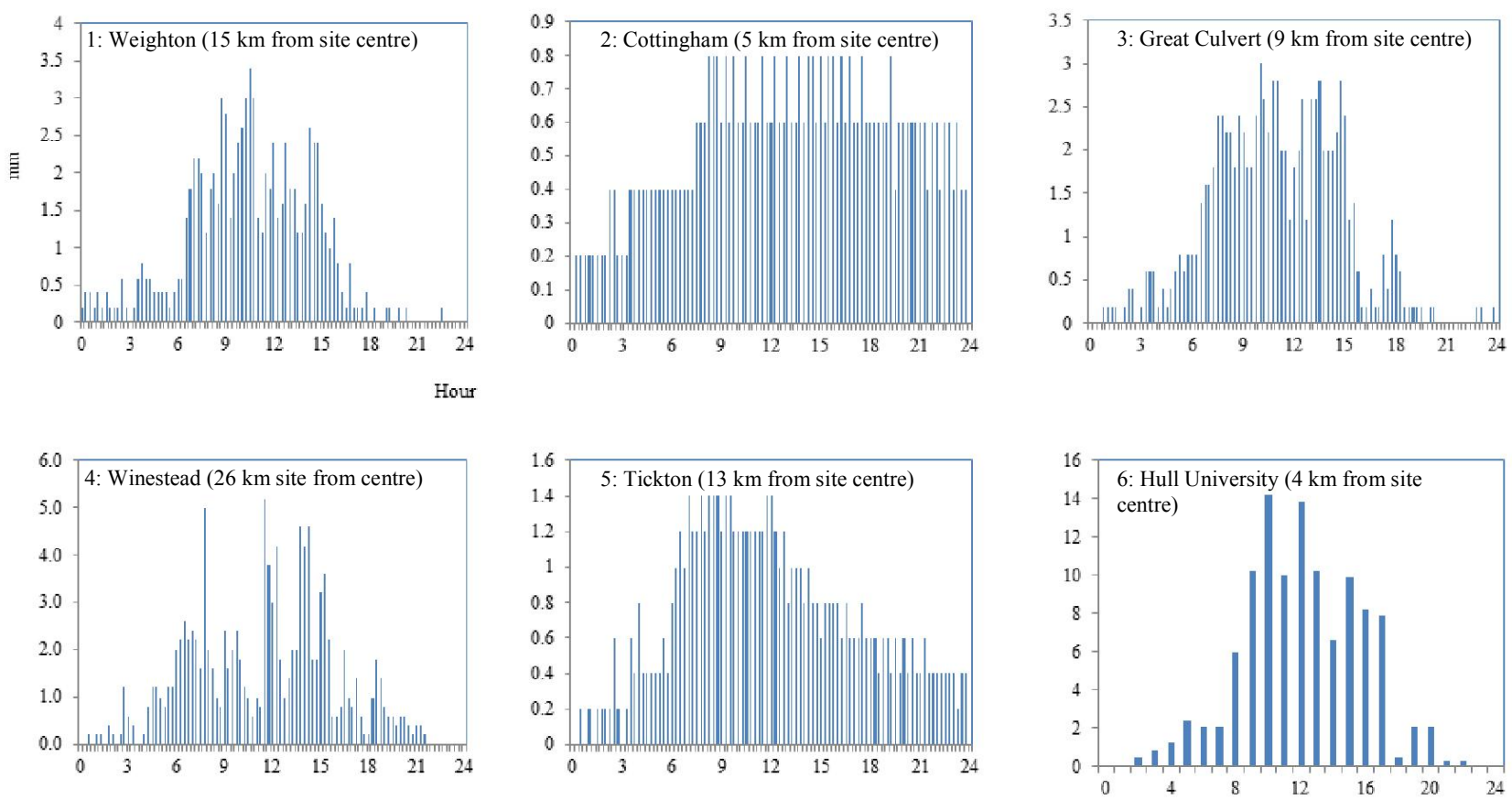

757 Figure 2: Rainfall hyetographs recorded at the gauging stations in and around the city. Unit: $\mathrm{mm} / 15$ minutes for sites 1$758 \quad 5 ; \mathrm{mm} / \mathrm{h}$ for site 6. 


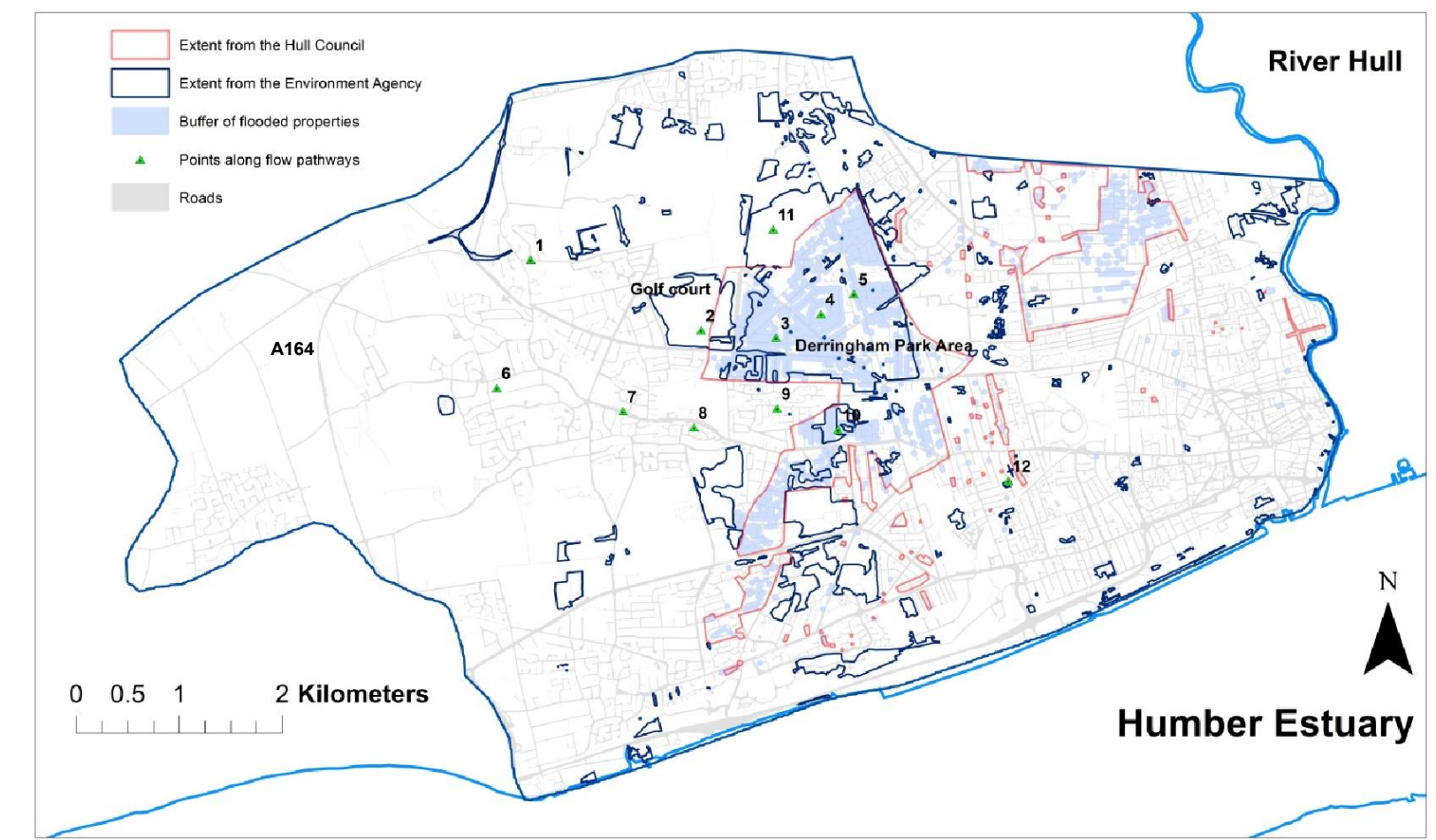

761 Figure 3: Inundation extent derived from ground survey and aerial photos (UK Environment Agency and Hull City 762 Council); and buffer of properties flooded (Hull City Council). 
(a)

$(10 \mathrm{~m})$

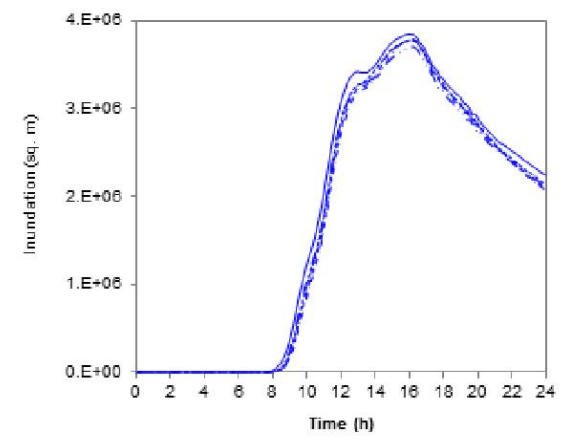

(20m)

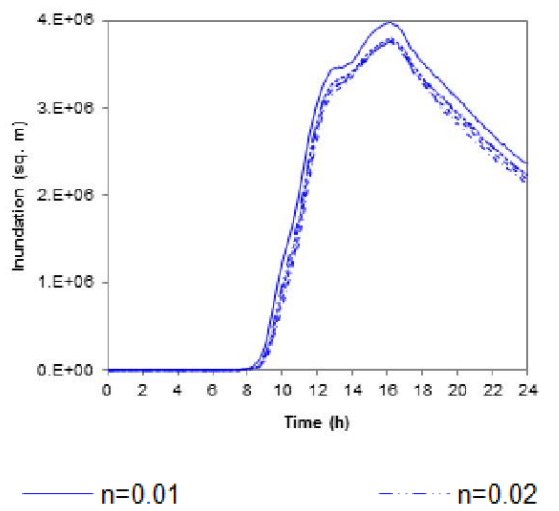

(b)
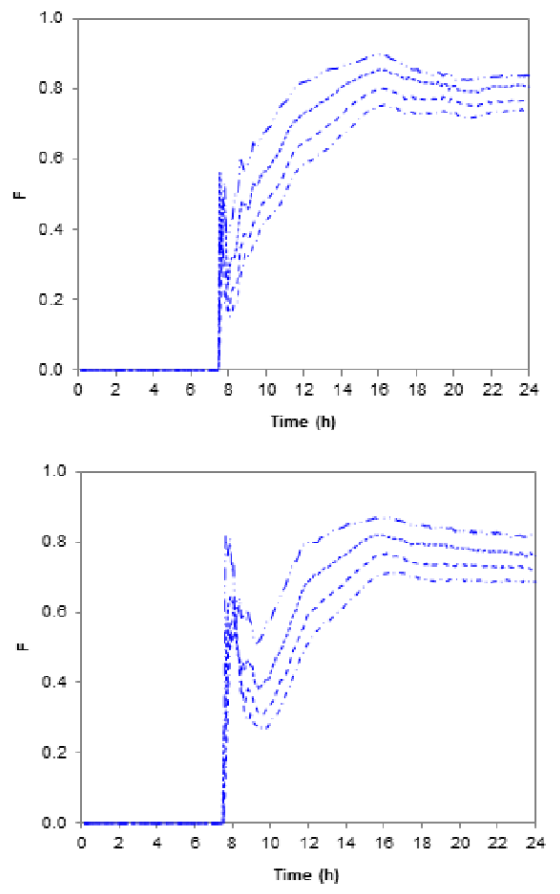

$n=0.03$ (c)
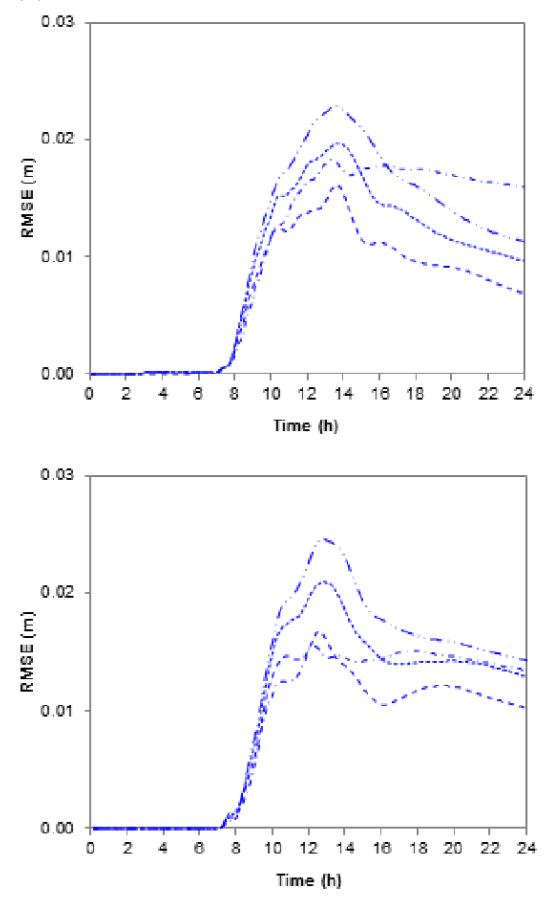

$n=0.04$ $n=0.05$

765 Figure 4: Sensitivity analysis to mesh resolution and roughness.

766 
Area

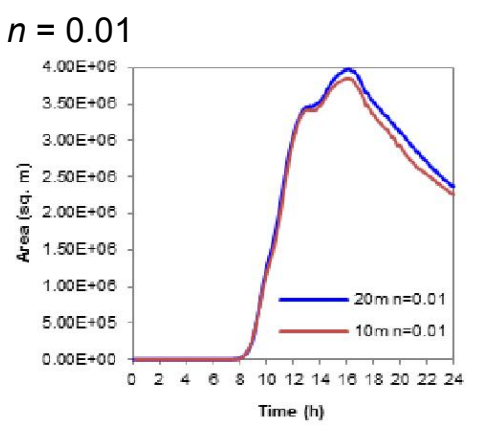

RMSE
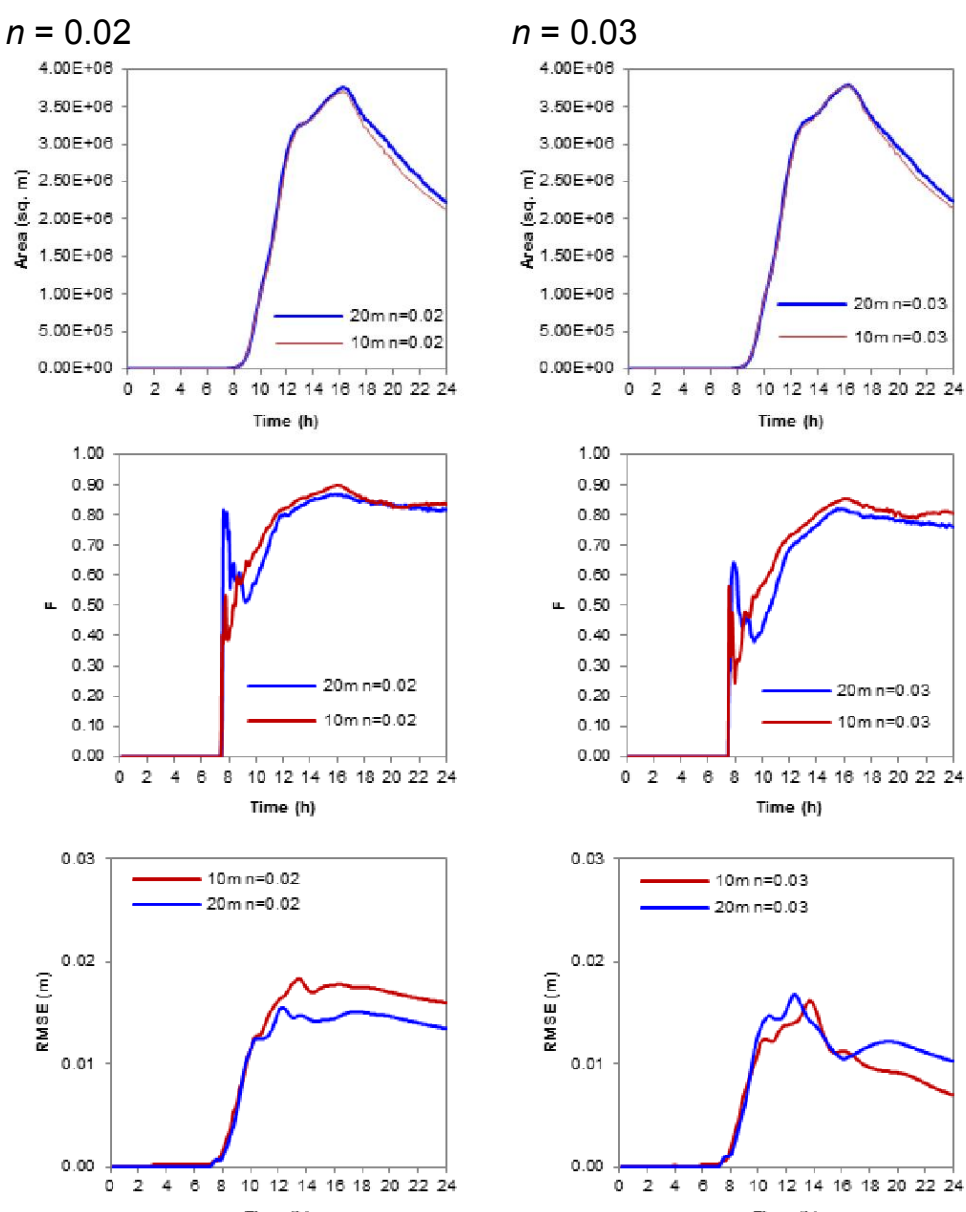

Time (t)
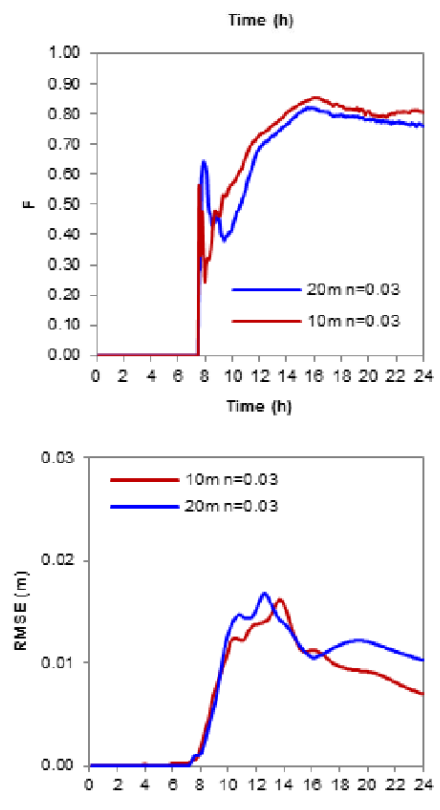

Time (h)
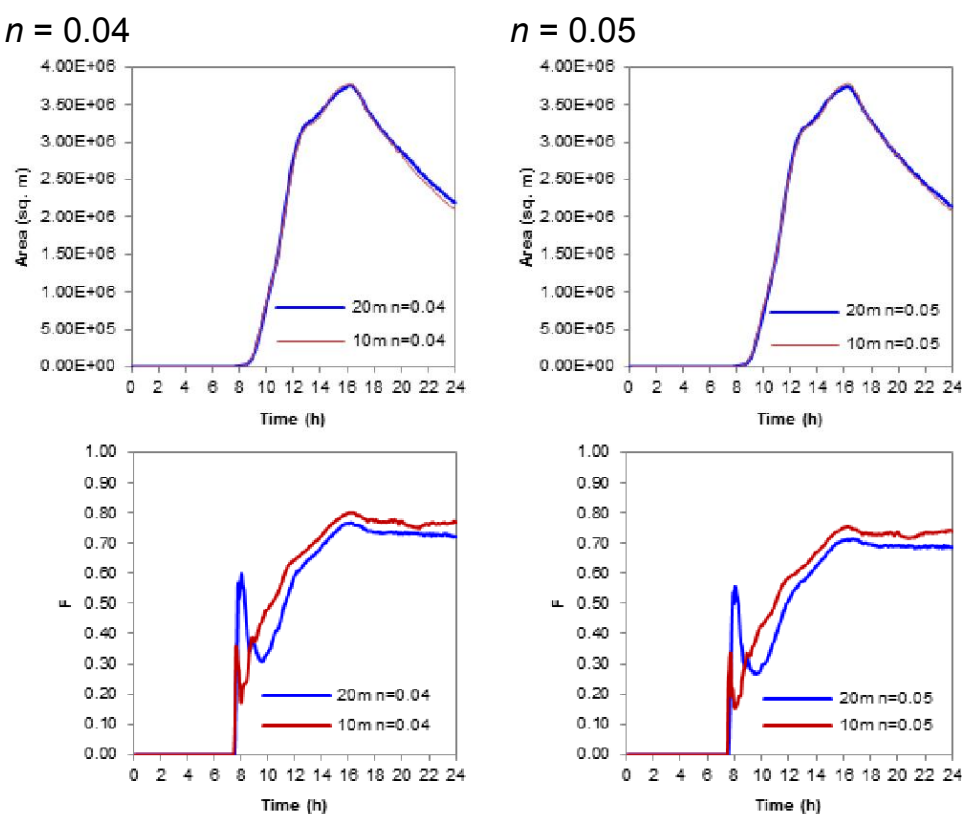

lime (n)
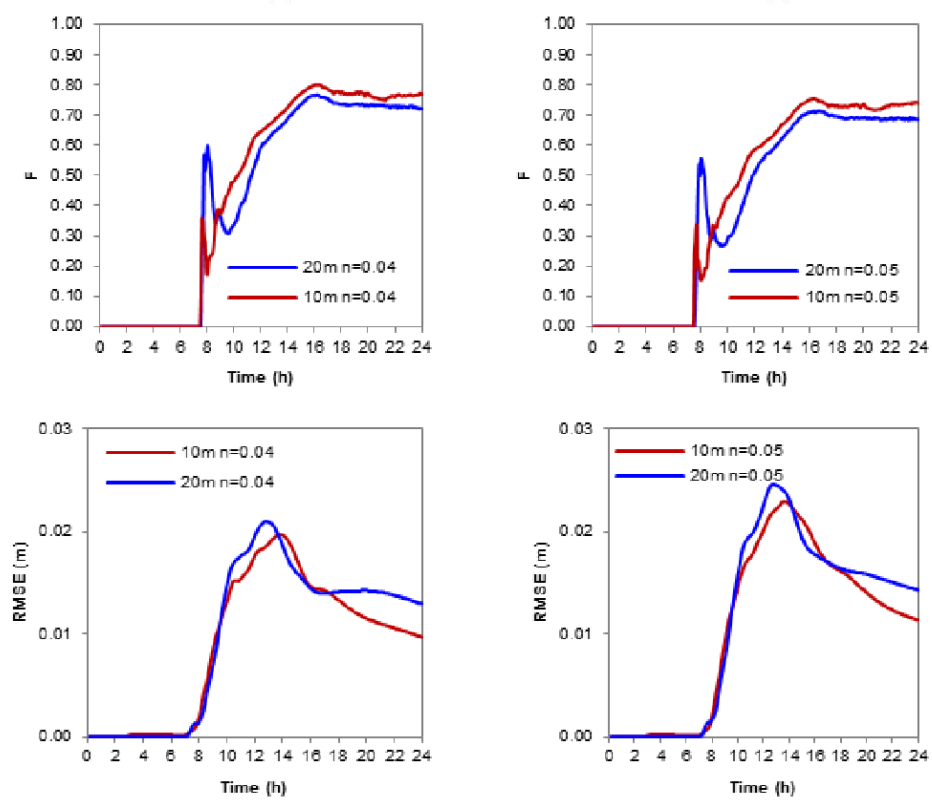

768 Figure 5: Model sensitivity to mesh resolution for different roughness values. 

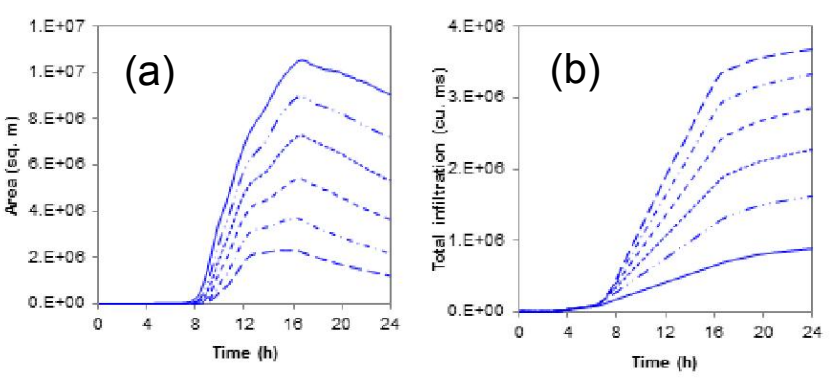

$20 \mathrm{~m} \mathrm{HC}=0.001$
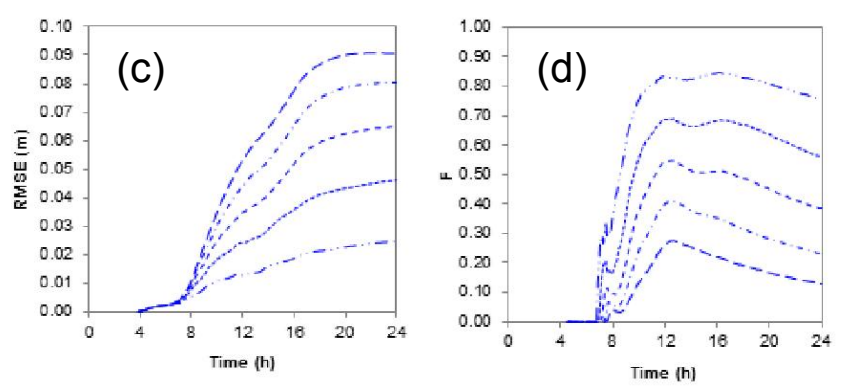

$20 \mathrm{~m} \mathrm{HC}=0.003$ $---20 \mathrm{~m} \mathrm{HC}=0.006$

769 Figure 6: Sensitivity analysis to hydraulic conductivity. 

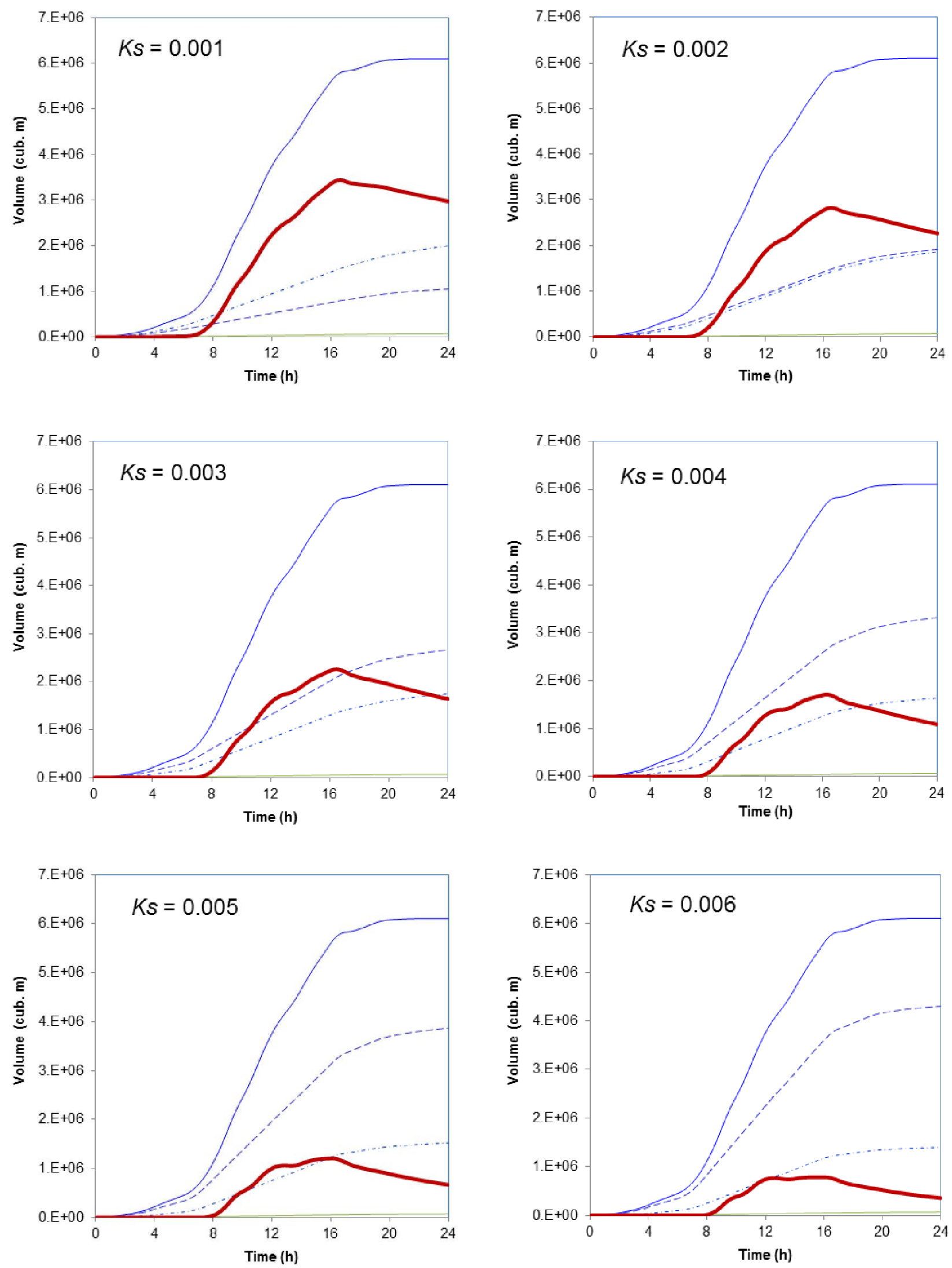

_ Rain total _--. Infiltration loss _-Evapotranspiration loss $\quad$-.... Drainage loss _ Balance

Figure 7: mass balance for simulations with different $K s$ values. 

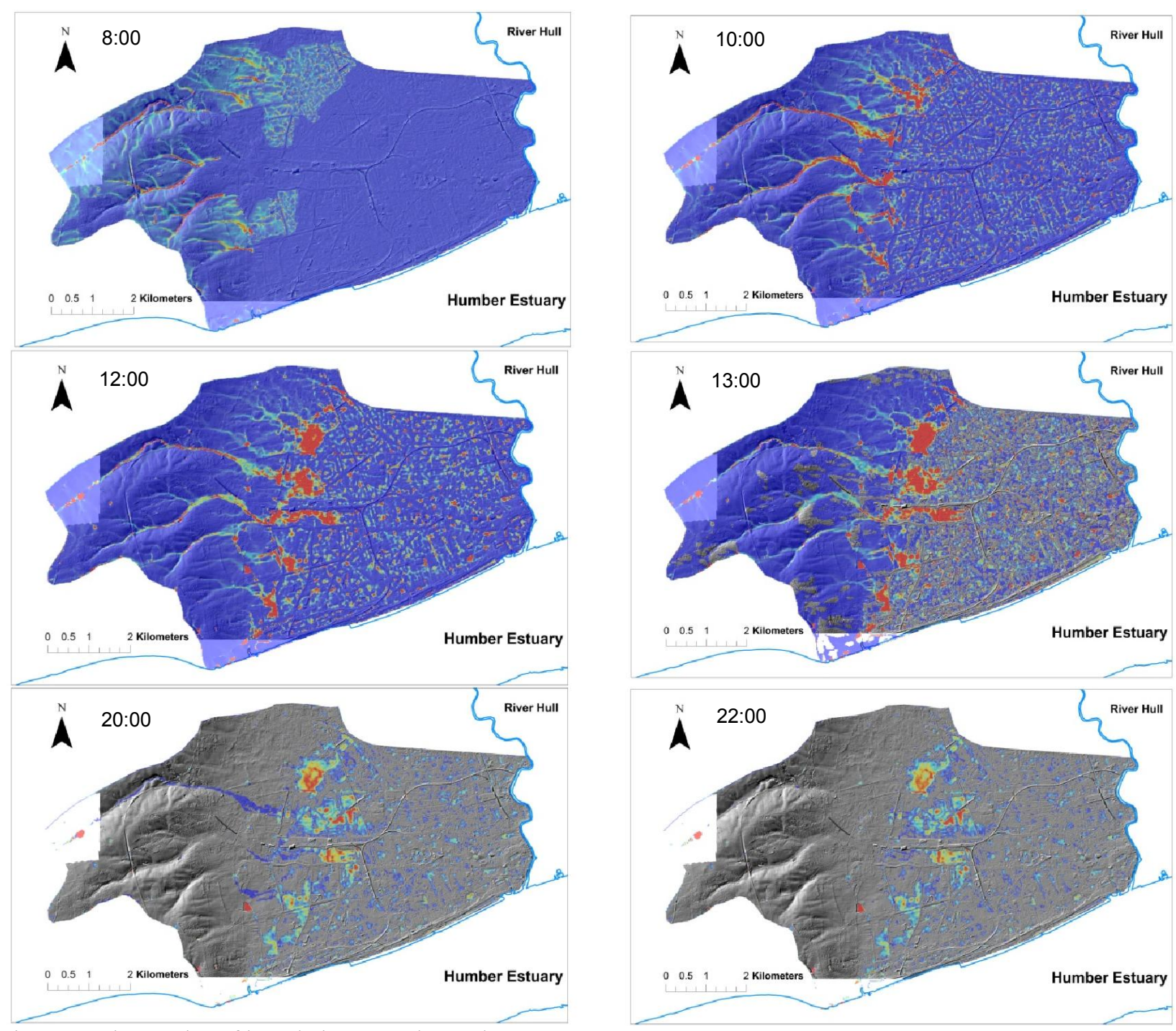

776 Figure 8: Time series of inundation over the study area. 
(a)

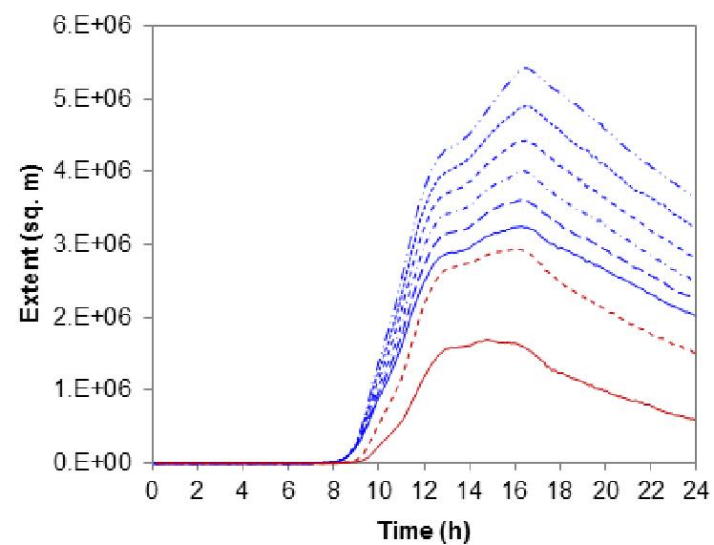

(c)

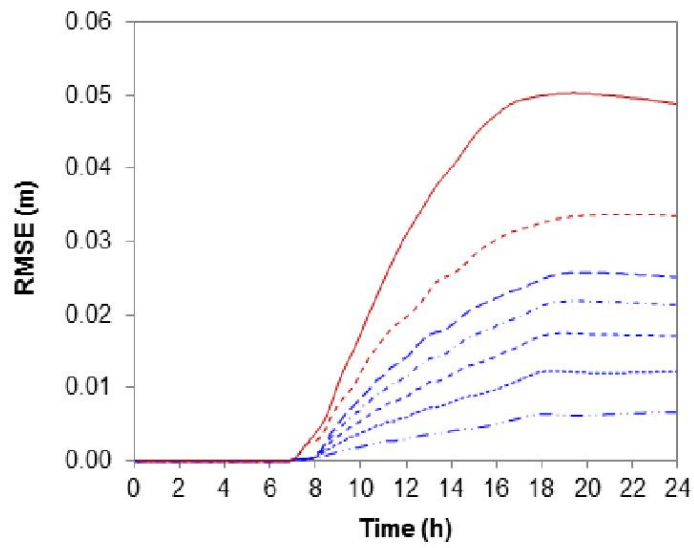

-....UD70_RD15

----UD110_RD15 (b)

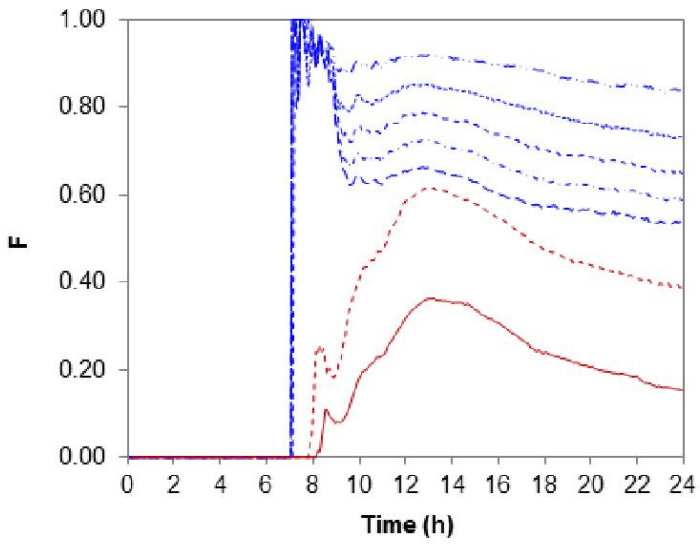

(d)

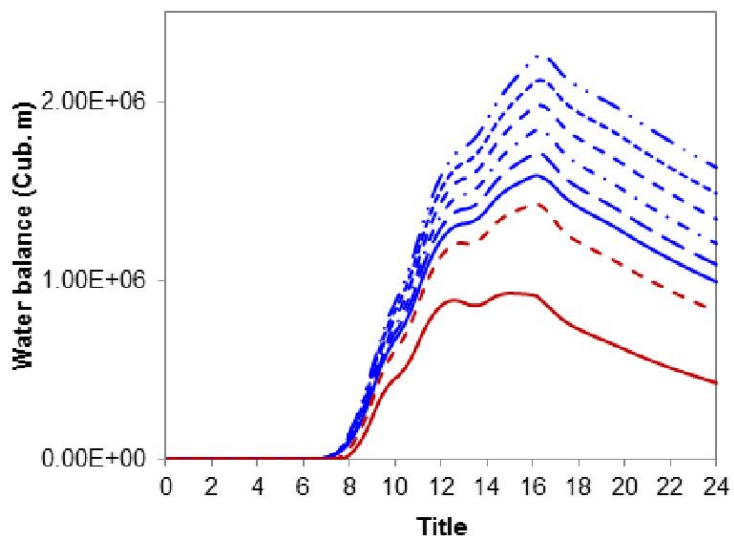

-..---UD90_RD15

…... UD100_RD15

— UD120 RD115

779 Figure 9: Impacts of improved urban drainage capacity scenarios: (a) total inundated areas; (b) F statistics compared to 780 the base simulation (UD70/RD15); (c) RMSE compared to the base simulation (UD70/RD15); and (d) water balance for 781 each simulation. 
(a)

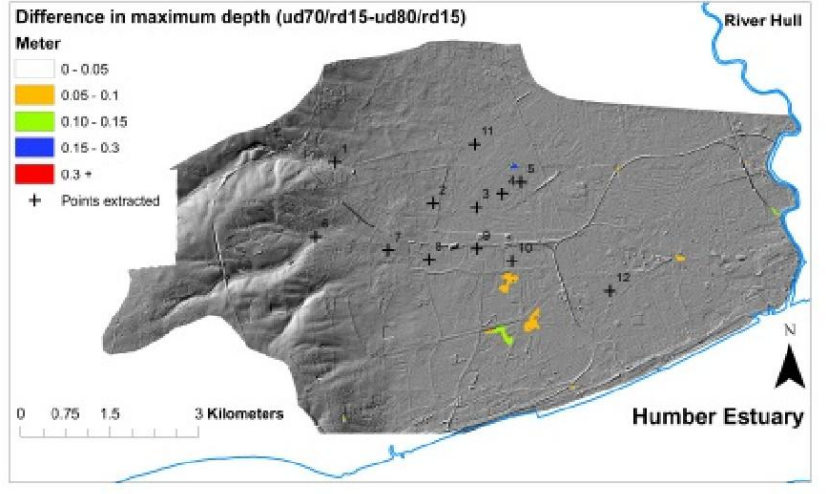

(c)

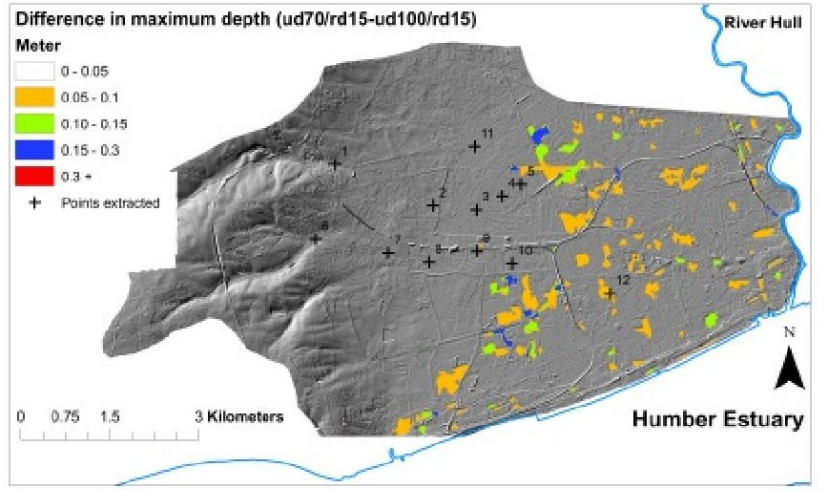

(e)

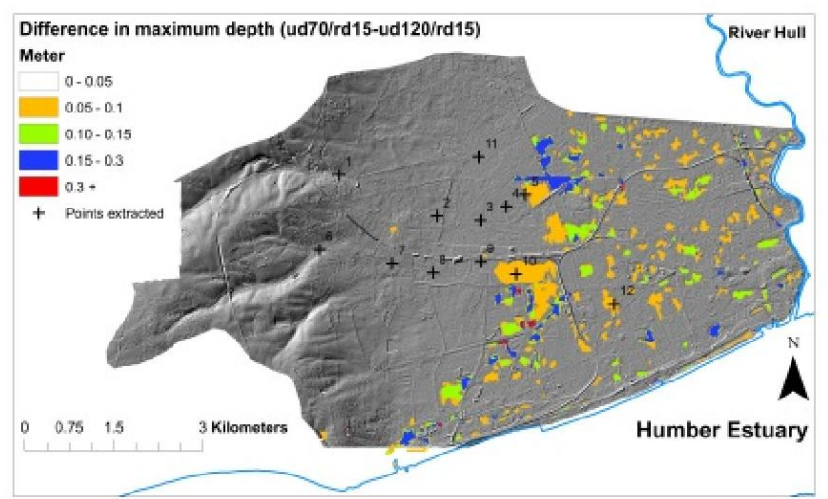

(b)

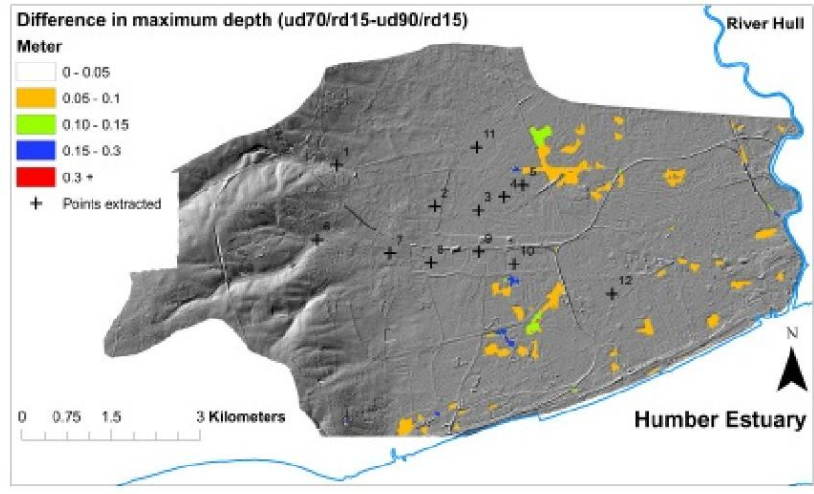

(d)

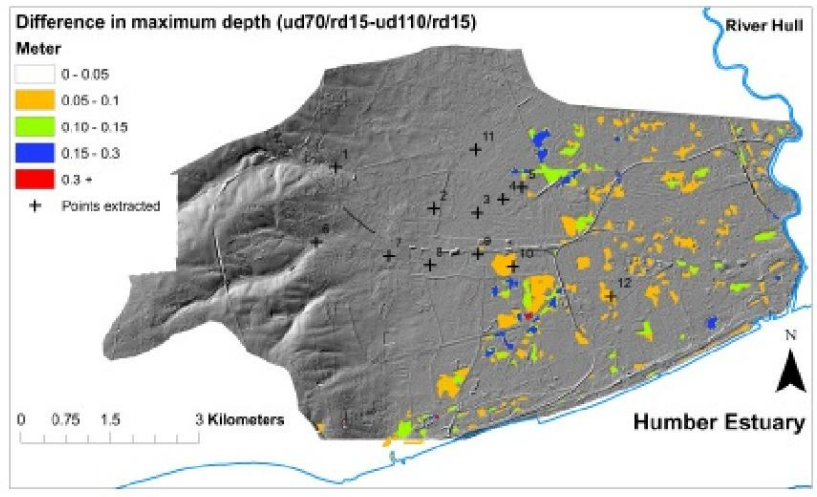

(f)

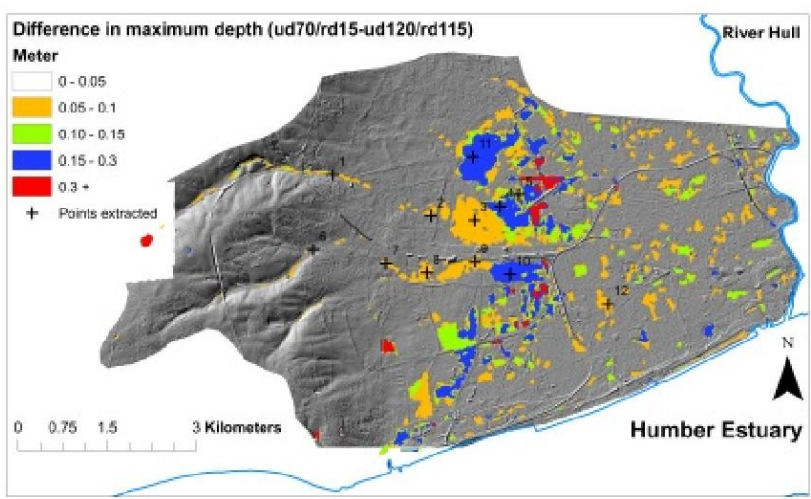

Figure 10: Predicted maximum water depth of the simulations with a $70 \mathrm{~mm} /$ day (a) and $120 \mathrm{~mm} /$ day (b) urban drainage capacity. Difference in the maximum water depth between the default simulation, and simulations with an improved urban drainage capacity of $120 \mathrm{~mm} /$ day (c). 
P1
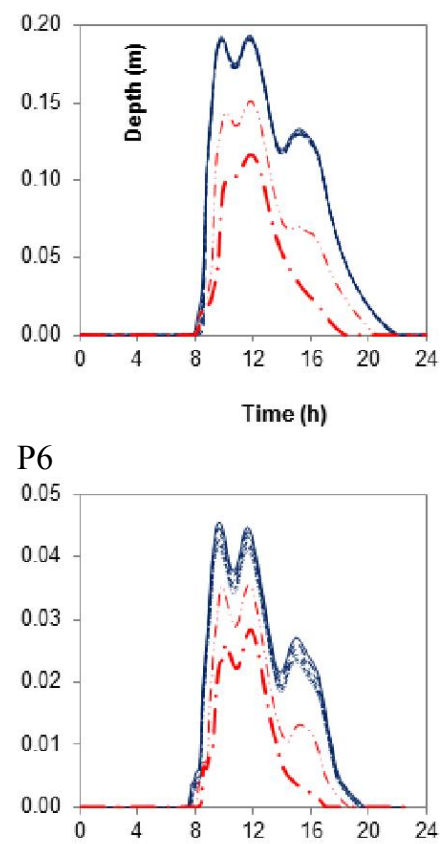

P5

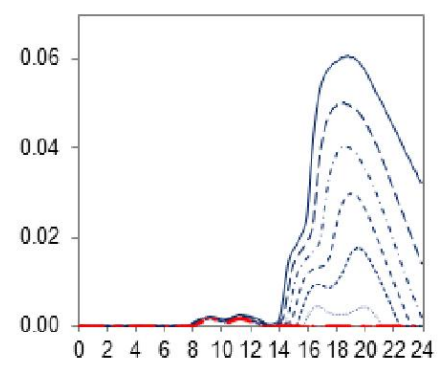

P2

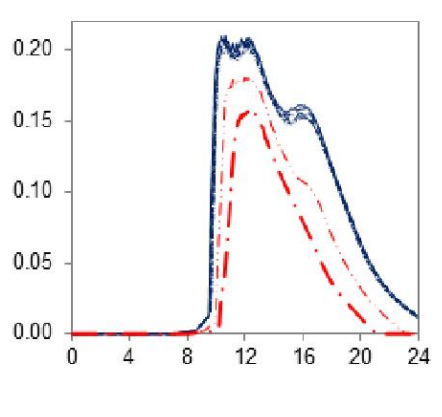

P7

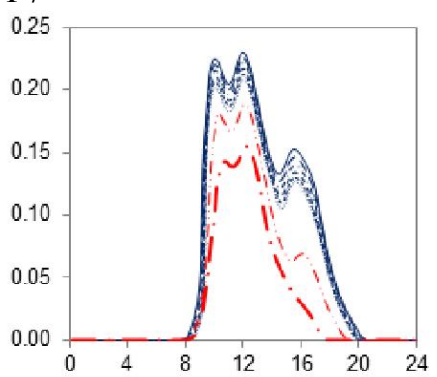

P10

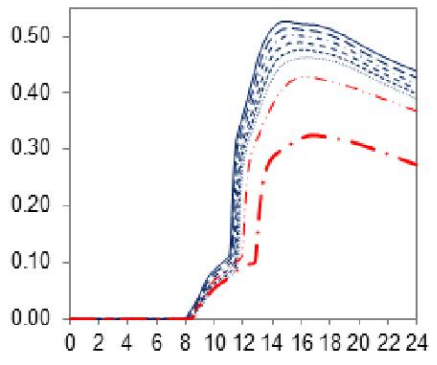

P3

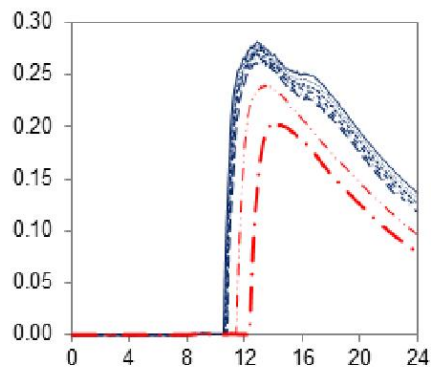

P8

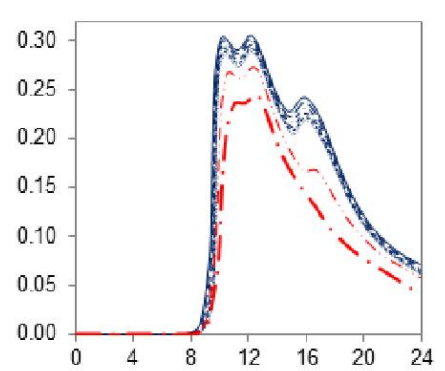

P11

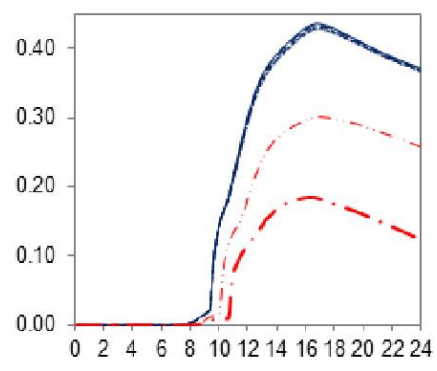

P4

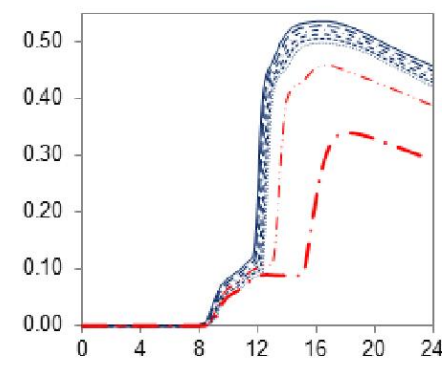

P9

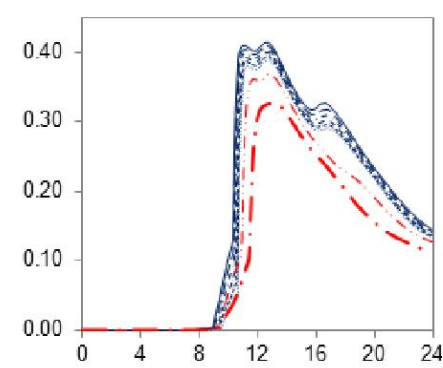

$\mathrm{P} 12$

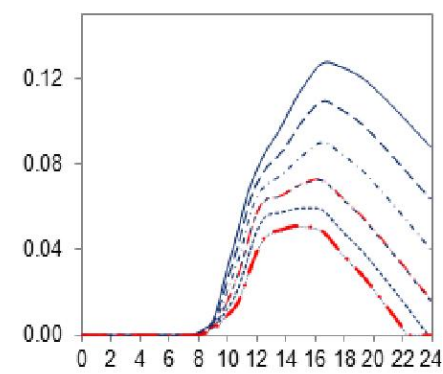

---UD120_RD15 -..-U UD110_RD15 -.--UD100_RD15 --.--- UD90_RD15

UD80_RD15 — UD70RD15 - - - UD100_RD75 - - UD120_RD115

Figure 11: Time series of water depths under urban drainage/storage improvement scenarios along two flow paths 
(a)

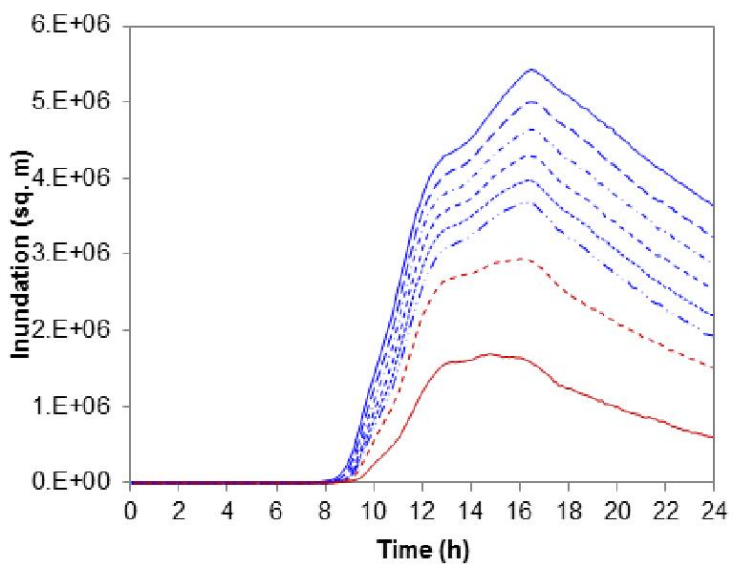

(c)
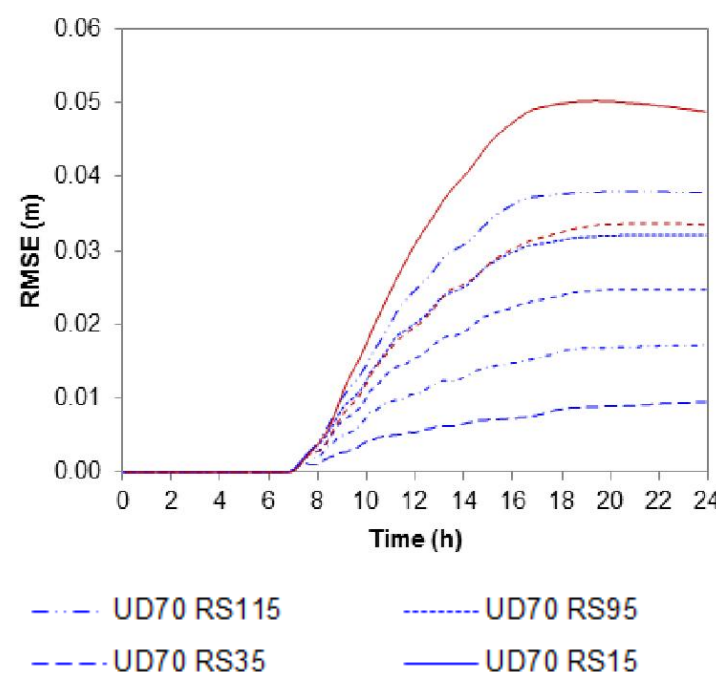

(b)

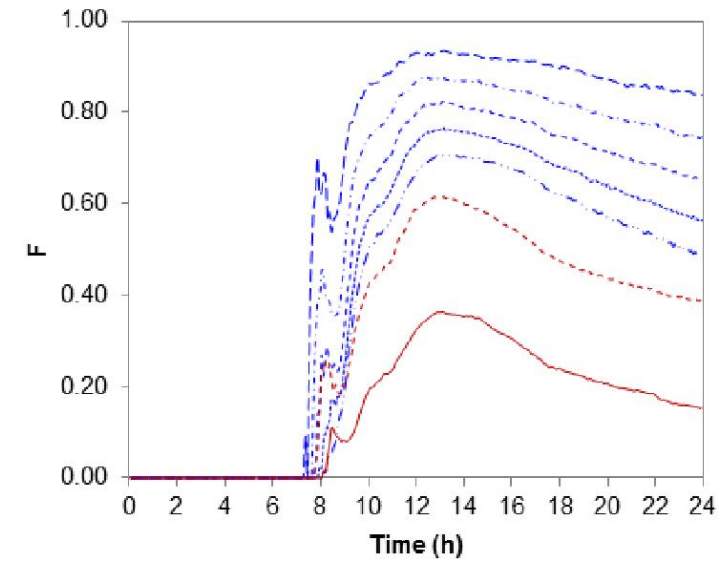

(d)

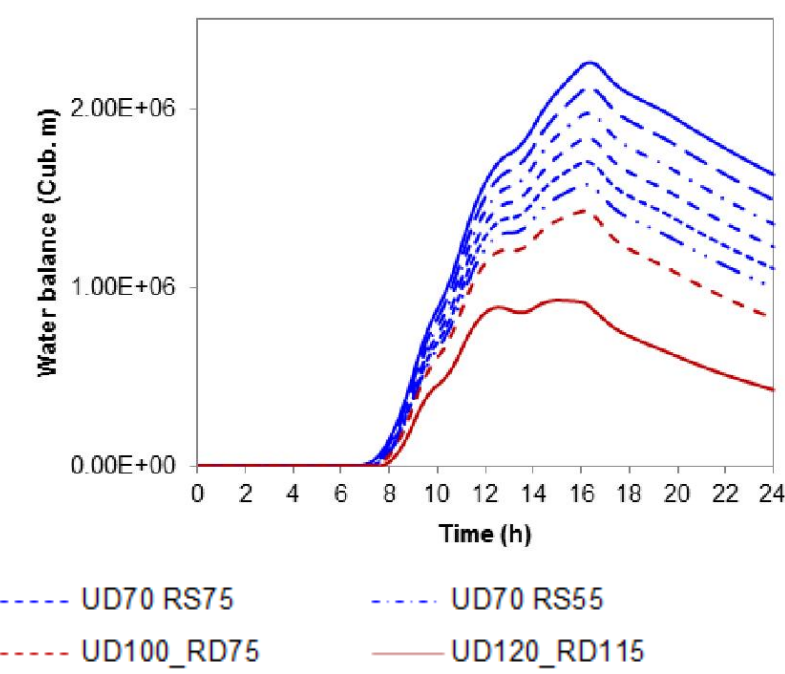

Figure 12: Impacts of improved rural land drainage and storage scenarios through land management: (a) total inundated areas; (b) F statistics compared to the base simulation (UD70/RD15); (c) RMSE compared to the base simulation (UD70/RD15); and (d) water balance for each simulation. 
(a)

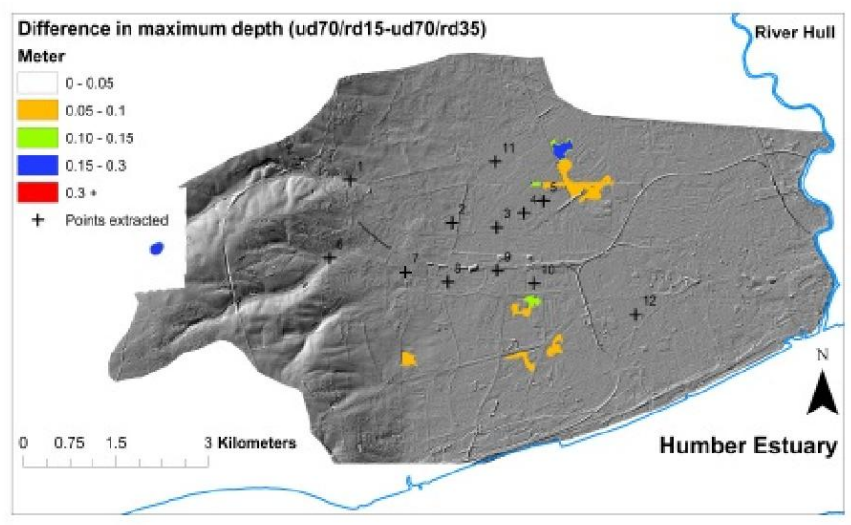

(c)

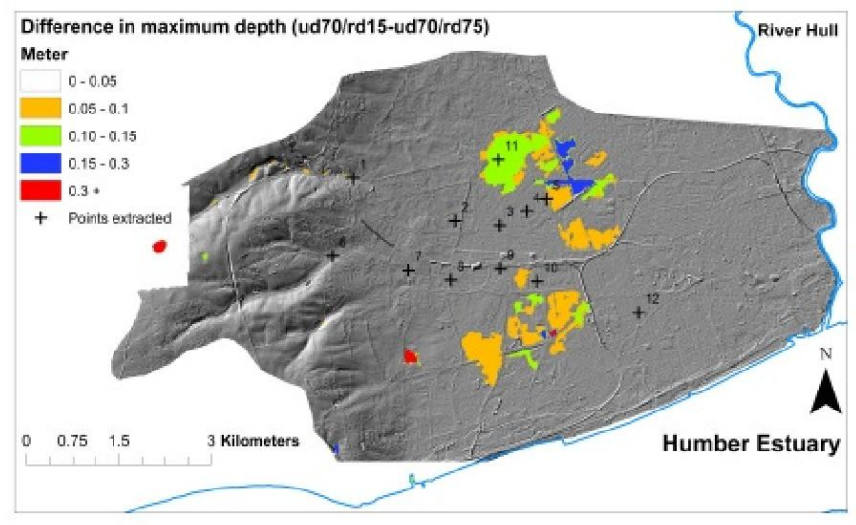

(e)

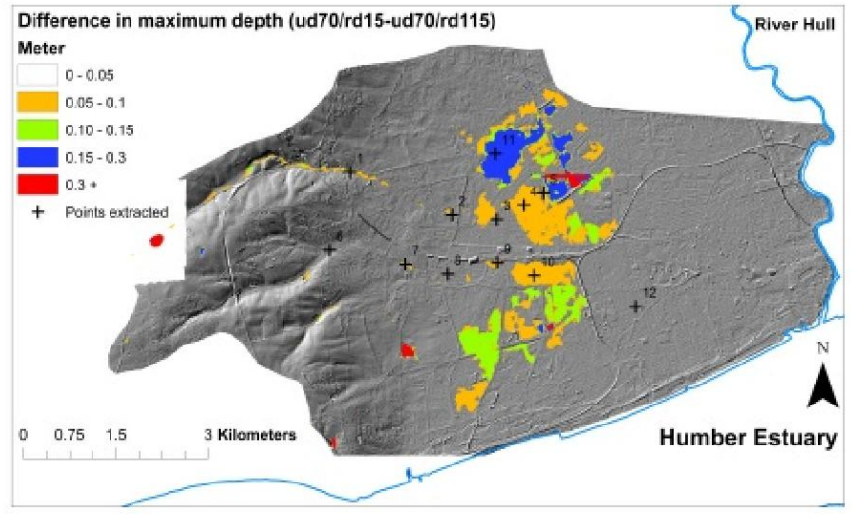

(b)

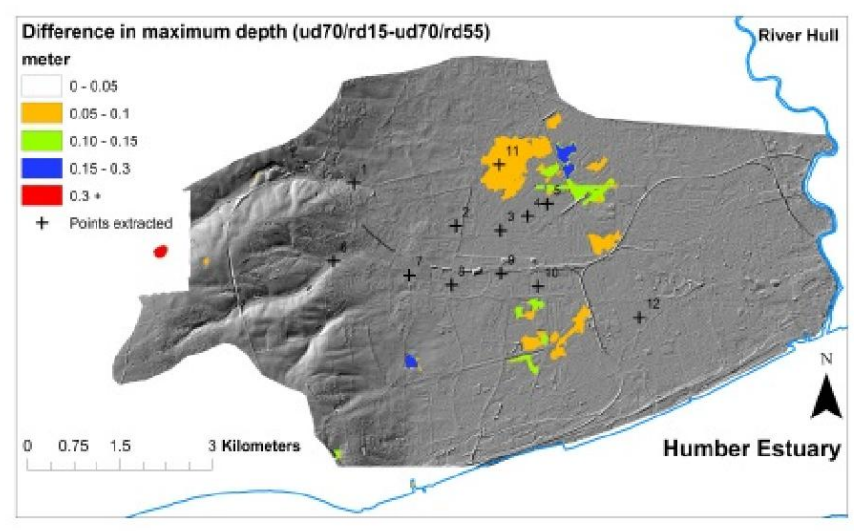

(d)

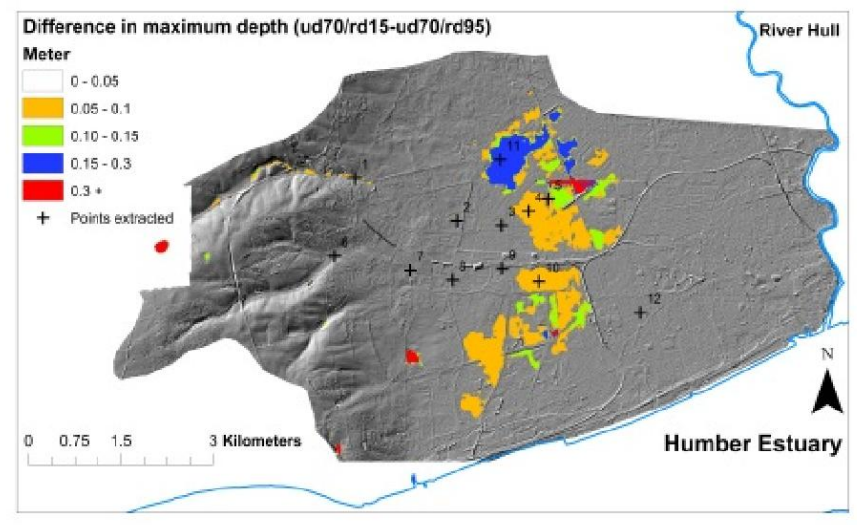

(f)

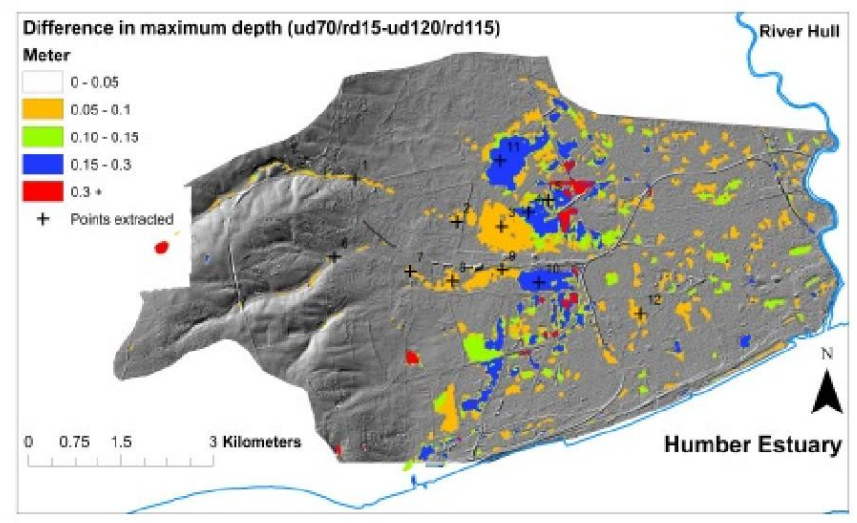

Figure 13: Difference in the maximum water depth predicted between the default simulation and the scenarios with improved rural drainage capacity: (a) $55 \mathrm{~mm} /$ day; and (b) $115 \mathrm{~mm} /$ day. 


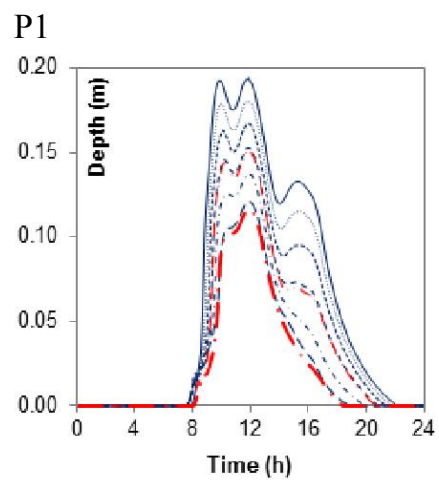

P2

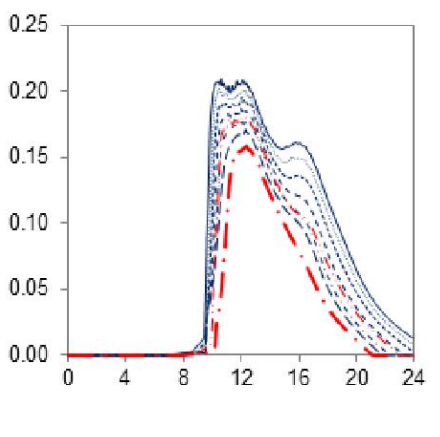

P6

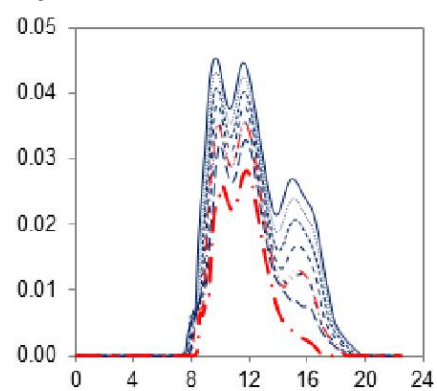

P7
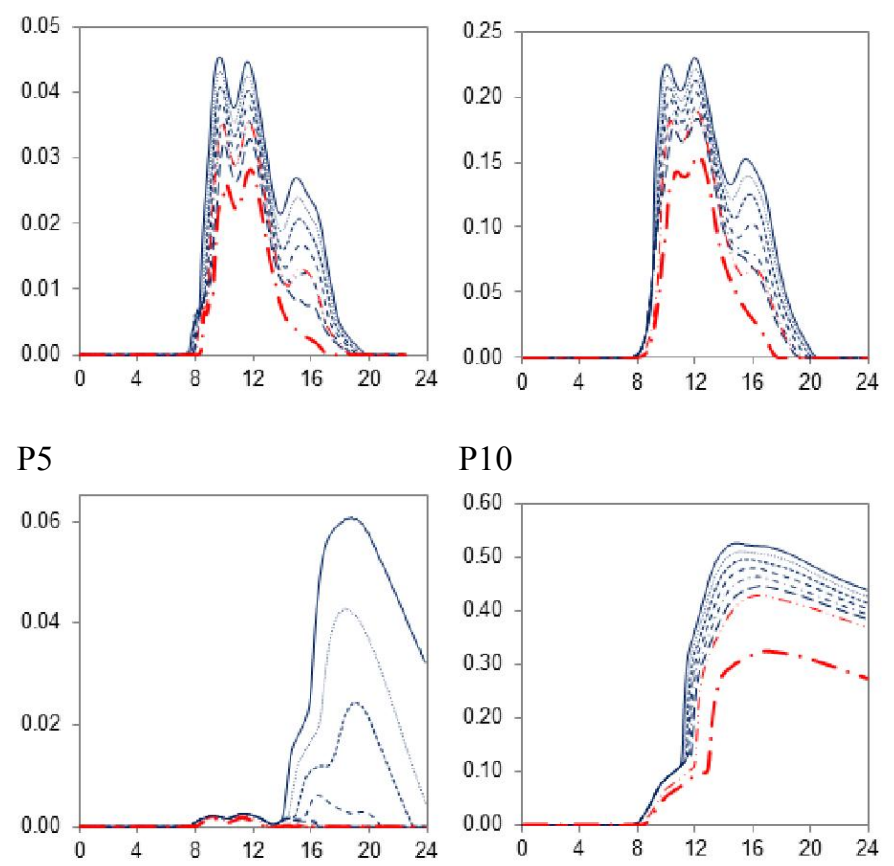

P10

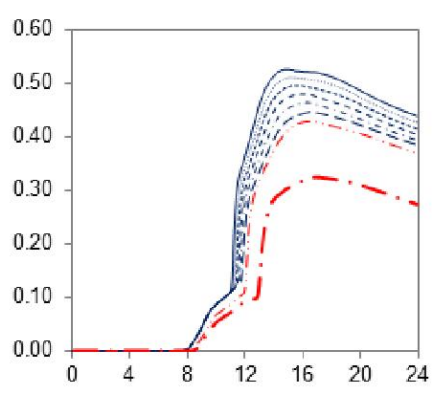

P3

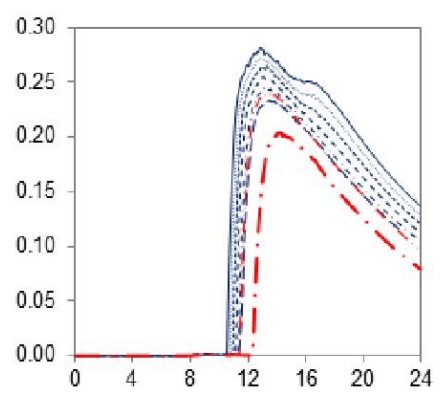

P8

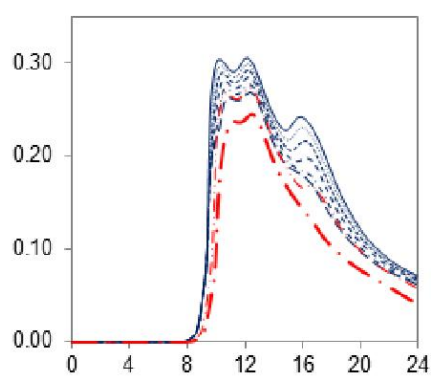

P11

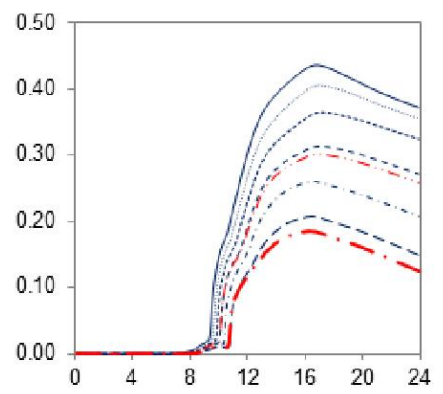

P4

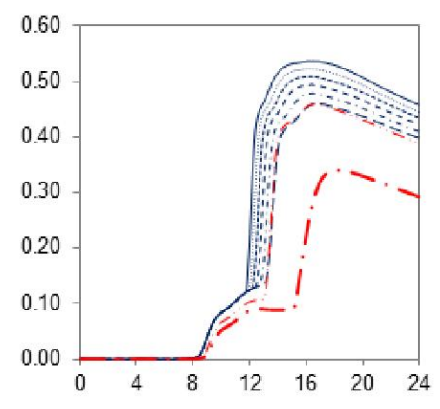

P9

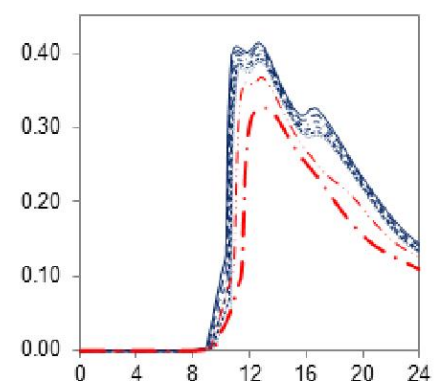

P12

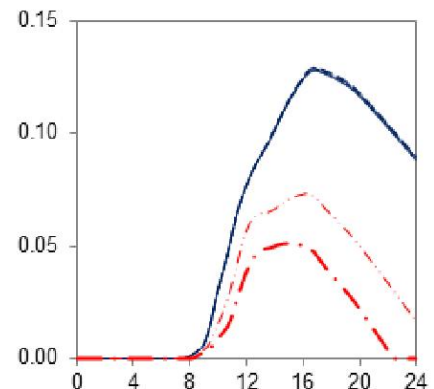

-_- UD70 RD115 -..... UD70 RD95 _- UD70 RD75 _-_-_- UD70 RD55 UD70 RD35 UD100_RD75 - - UD120_RD115

804 Figure 14: Time series of water depths under rural land management scenarios along two flow paths (Figure 3). 
(a)

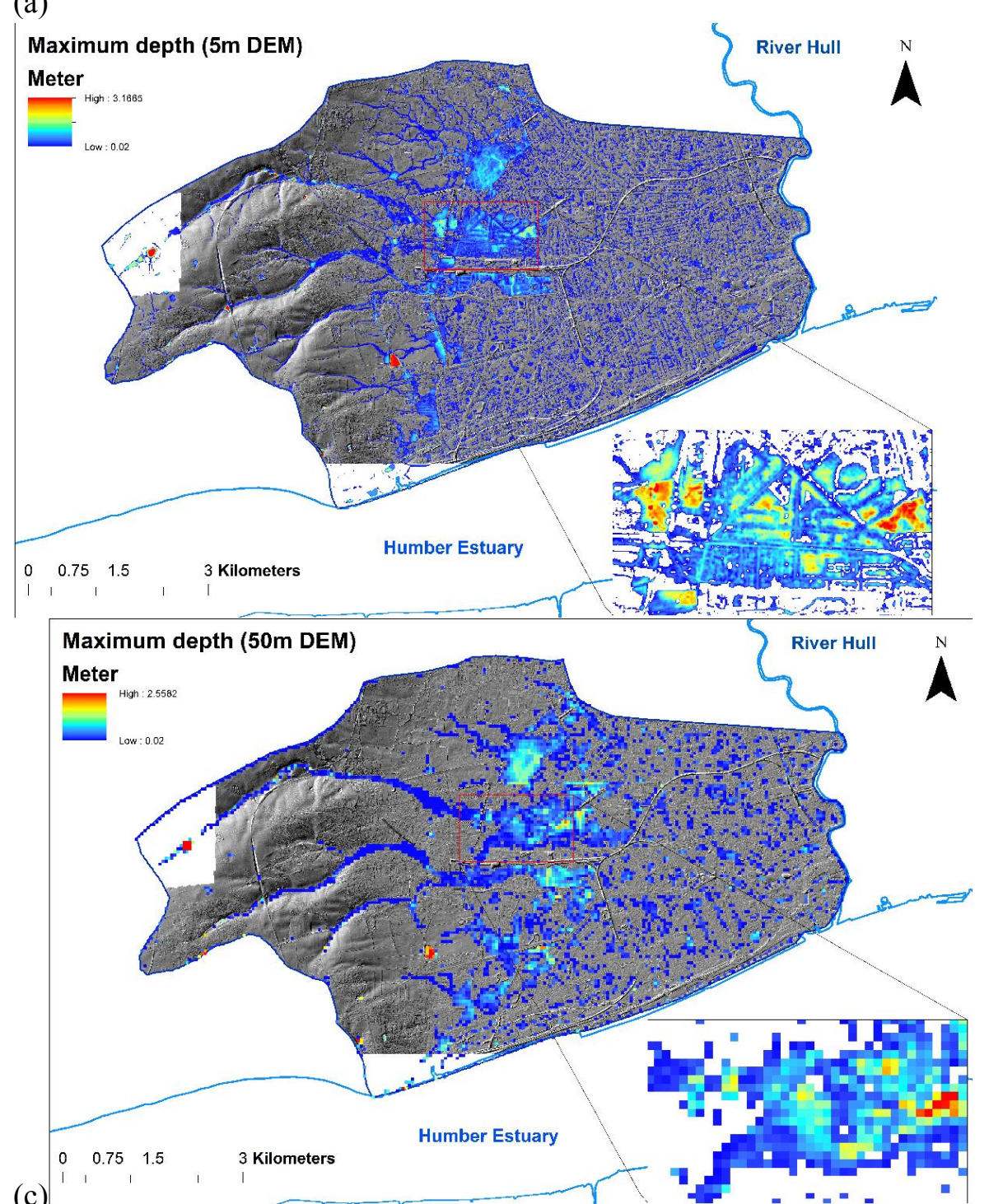

(c) 1

Figure 15: Effects of model resolution: (a) 5 m DTM; (b) 10 m DTM; (c) $50 \mathrm{~m} \mathrm{DTM}$, and (d) $100 \mathrm{~m}$ DTM. (b)

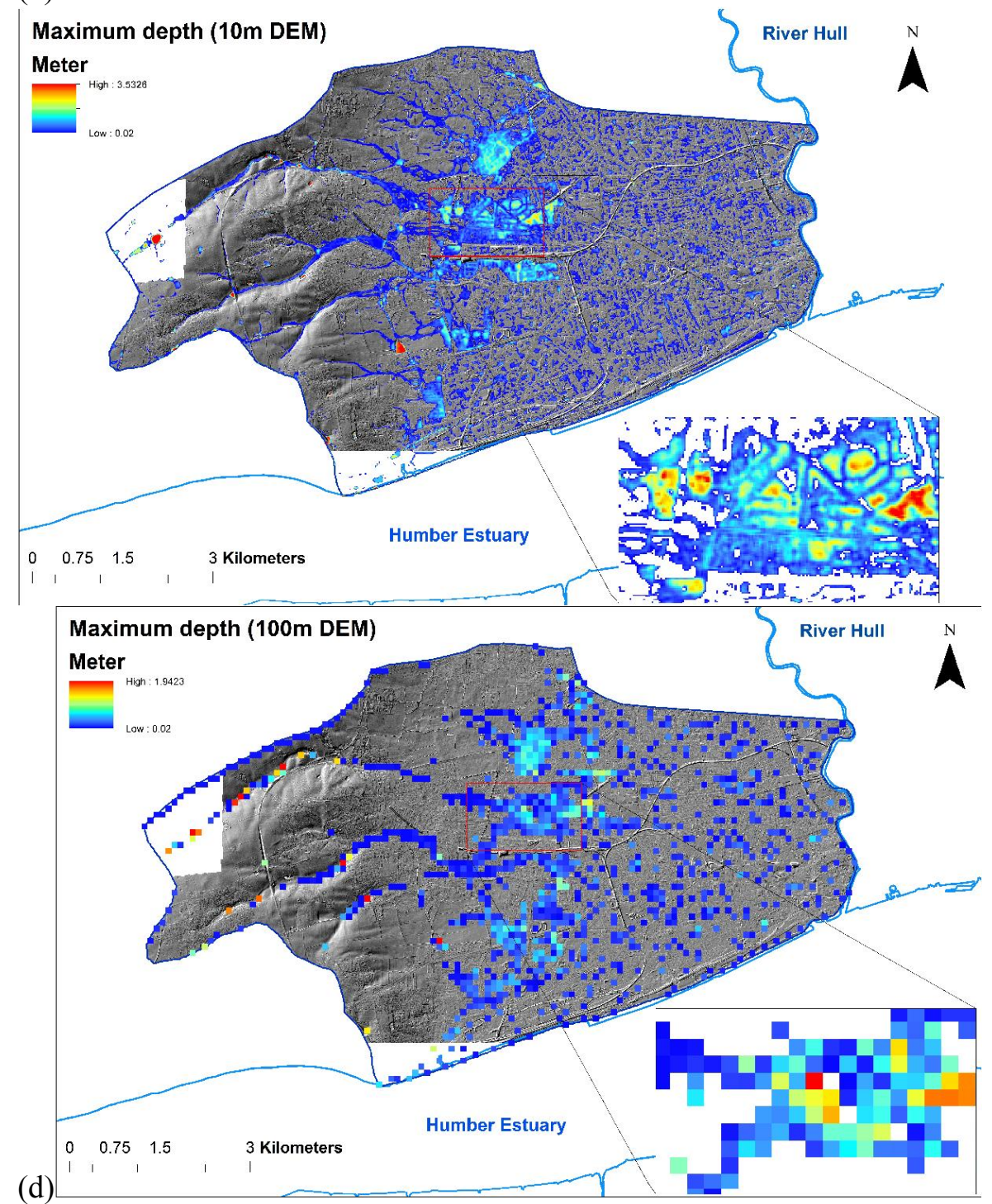


806 